\title{
Wealth of Tongues: Why Peripheral Regions Vote for the Radical Right in Germany
}

\author{
Daniel Ziblatt Harvard University \& WZB \\ Hanno Hilbig Harvard University \\ Daniel Bischof Aarhus University
}

February 2, 2023

\begin{abstract}
Why is support for the radical right higher in some geographic locations than others? This paper argues that what is frequently classified as the "rural" bases of radical right support in previous research is in part the result of something different: communities that were in the historical "periphery" in the center-periphery conflicts of modern nation-state formation. Inspired by a classic state-building literature that emphasizes the prevalence of a "wealth of tongues" (Weber 1976) or nonstandard linguistic dialects in a region-as a definition of the periphery, we use data from more than 725,000 geo-coded responses in a linguistic survey in Germany to show that voters from historically peripheral geographic communities are more likely to vote for the radical right today.
\end{abstract}

word count=abstract 119, limit: 150 words.

full manuscript (excluding abstract) $=11,780$, limit: 12,000 words.

\footnotetext{
Corresponding Email: dziblatt@g.harvard.edu. We are thankful for comments by Christian Breunig, Noah Daponte-Smith, Noam Gidron, Peter Hall, Silja Häusermann, Thomas Kurer, Evan Lieberman, Pauliina Patana, Sergi Pardos Prado, Roman Senninger, and Markus Wagner. We also thank all participants and their thoughtful feedback at our panels at the 2019 EPSA and APSA conferences, as well as seminar audiences at WZB Berlin and Harvard University. We also thank for a range of suggestions made during an invited talk by Daniel Bischof at the university of Mannheim and university of Konstanz. We are extremely thankful to Alfred Lameli and Adrian Leemann for sharing their linguistic data with us on which this article is based upon. Daniel Bischof thankfully acknowledges funding from the Swiss National Science Foundation (SNF Ambizione Grant, NO. 179938).
} 


\section{Introduction}

Why is support for the radical right higher in some geographic locations than others? Some scholars emphasize the economic roots of the political geography of radical right support, showing how regions with a declining manufacturing base and heightened economic hardship leave them more vulnerable to the appeals of the radical right (Broz, Frieden, and Weymouth 2020; Colantone and Stanig 2018b; Autor et al. 2016). Other scholarship highlights how radical right support reflects an urban-rural divide, noting that it can emerge in rural regions due to heightened resentment over the countryside's (self-)perceived marginality (Cramer 2012, 2016; Cremaschi et al. 2022), a different constellation of social values in sparsely populated areas (Rodden 2019; Maxwell 2019, 2020), or the politicization of place-based identity in rural regions (Munis 2020; Fitzgerald and Lawrence 2011; Fitzgerald 2018; Bolet 2021)

This paper proposes an alternative perspective on the spatial bases of radical right voting. Rather than only reflecting contemporary economic dynamics or urban-rural differences, we emphasize the enduring impact of the historical "center-periphery" conflict that emerged out of the $19^{\text {th }}$ century nation state formation process (Lipset and Rokkan 1967; Hechter 1972; Weber 1976; Hooghe and Marks 2016). Regions that were historically in the periphery during the building of nation-states possessed lowstatus cultural markers-chief among them local dialects and languages-that left citizens defensive of their local communities and alienated from the national political community (Rokkan and Urwin 1983; Rokkan 2009). We revive these arguments and extend them by suggesting that what appears to be mainly a "rural" phenomenon of radical right support in recent research is at least in part significantly anchored in something different: communities that were in the historical "periphery" during the center-periphery conflicts that shaped the formation of modern nation-states (Lipset and Rokkan 1967).

Our main contention is that voters from historically peripheral geographic communities are more likely to vote for the radical right today. The mechanism behind this proposition is that citizens from geographic regions with persistent and clearly 
identifiable lower-status cultural markers such as a nonstandard dialect or language are today more prone to feel "left behind" with higher levels of anti-elite sentiment and out-group resentment. This motivates voting for challenger parties such as radical right populist parties. We expect also that this pattern becomes even stronger in moments in which the perception of cultural threats'-such as the large influx of refugees-emerges, and especially so if populist radical right parties frame the influx of refugees as such a threat.

We highlight the role of one attribute that classic works on state formation (Lipset and Rokkan 1967; Hechter 1972; Scott 1998) identify as a hallmark of peripheral communities, but that political scientists to date have not sufficiently explored: dialect and dialectal distance from a national standard language. We also draw on insights from the field of sociolinguistics that show that language or dialect are a source of place-based social identity (Labov 1963; Remlinger 2009; Becker 2009). Regions that are, in dialectal terms, "closer" to the national standard language reflect the accumulation of a history of greater economic interaction and cultural exchange with the political center. By contrast, residents in regions with more distinctive dialects are likely to be culturally distant from the political core and part of geographicallycircumscribed social networks that do not extend far beyond their place of residence, and as a result are likely to possess stronger local place-based cultural markers. Focusing on the German case-a country rich in dialects-, we rely on dialectal data of more than 725,000 geocoded responses stemming from work by Elspaß (2005) and Leemann, Derungs, and Elspaß (2019), which then enables us to measure how distinct a given regional dialect is compared to standard German.

We test our argument by studying the electoral rise of the radical-right Alternative für Deutschland (AfD) party in the 2010s in Germany. We combine the Leemann, Derungs, and Elspaß (2019) dialectal distance measure with county-level electoral results from the 2017 federal elections and individual public opinion data from the German Longitudinal Election Study (GLES). We find support for the hypothesis that peripheral communities with a higher prevalence of nonstandard German are more 
predisposed to radical-right parties. In both county-level and individual data, greater dialectal distance to standard German is associated with a significant and substantively meaningful increase in voting for the radical-right AfD party. We then present evidence, consistent with existing theory (Enos 2014), that out-group hostility is activated in these communities by an external threat: The correlation between dialectal distance and radical-right voting is strongest when refugee inflows were at their peak during the recent so-called "refugee crisis". In terms of mechanisms, our analyses reveal that residents in peripheral counties on average place themselves lower on a social status scale and are significantly more likely to support strict limits to migration (out-group hostility) and to hold populist attitudes driven by a rejection of the political elite (anti-elitism).

To ensure that our results are not driven by unobserved confounders, we conduct a range of additional tests. We show that our results are robust to the inclusion of standard economic and demographic covariates, both on the aggregate and the individual level. Our results remain unchanged when we control for nationalism, attachment to the locality, urbanization, migration, geographical isolation, and historical patterns of racism and Anti-Semitism, among a range of other controls. In addition, we include increasingly fine-grained fixed effects to demonstrate that unobserved regional heterogeneity does not underlie our findings. Following Imbens (2003), we conduct sensitivity analyses by estimating how strong an omitted confounder would need to be to control away the main finding (Cinelli and Hazlett 2020). We show that a hypothetical omitted variable as twice as strong as the unemployment rate would not change the substantive conclusions of our analysis. Taken together, these additional tests strongly suggest that our results are not a result of unmeasured confounding.

Our paper makes three key contributions to the current literature on the emergence of the radical right. First, our argument joins a growing literature (Cramer 2012; Fitzgerald 2018; Munis 2021, 2020; Bolet 2021) that allows us to move beyond the simplified dichotomy between "urban" and "rural" communities by demonstrating that the historical position and experiences of rural communities in the nation-state for- 
mation process have varied in important ways. This then results in a more nuanced theoretical and empirical perspective on the role of the "periphery" in politics and how it continues to link with political elites, outsiders, and voting behavior today. In particular, we build on Munis (2020) in emphasizing how place-based identity fuels radical right support. Second, to the best of our knowledge we provide a new and unique measure for the center-periphery conflict by using non-standard dialects-a direct correlate of the this conflict-in our research design. While dialects are particularly pronounced in the German language, they are present in important ways in other languages. We draw on findings in sociolinguistics (Labov 1963; Remlinger 2009; Becker 2009) that link dialect to place-based identity, suggesting avenues for research on questions of local political cultures. Third, an implication of our finding is that periods of radical structural change-such as processes of nation-building, re-unification or even separation-have long-running consequences for how the affected perceive their status within their domestic community. While political scientists often take a "snapshot" view of politics in which we look for causes temporally proximate to outcomes, drivers of our politics may often be rooted in ruptures deep in the past (Pierson 2011). Past conflicts' resolutions (e.g. center-periphery conflict), in turn, may get reactivated by exogenous shocks such as war and immigration waves. While research in economics has already integrated some of these ideas (Voigtländer and Voth 2012; Alesina, Giuliano, and Nunn 2013), political science still stands at the beginning of understanding how the persistence of deep-rooted local culture affects political perceptions and behavior (Acharya, Blackwell, and Sen 2016; Munis 2021; Haffert 2021).

\section{Why the Radical Right Clusters in Specific Geographic Locations}

A large amount of research on the radical right weighs the importance of alternative individual correlates of voter support of radical right parties (Inglehart and Norris 2016; Gidron and Hall 2017; Fitzgerald 2018; Guiso et al. 2020). But recently, there has also been attention to the fact that the populist radical right parties' electoral 
support clusters in specific geographic locations (Fitzgerald and Lawrence 2011; Eliasoph 2017; Munis 2021; Bolet 2021; Cremaschi et al. 2022). Scholars have observed, for example, that in Europe and North America, economically thriving cities are locations of "cosmopolitan" attitudes, and also show less support for the radical right. By contrast, the countryside and regions in economic decline appear to be locales where radical right parties do well electorally and where the Brexit movement found a great deal of its support in 2016. One popular account portrays this as the divide between cosmopolitan "anywheres" who are not connected to any particular location and parochial "somewheres" who are deeply attached to their home communities (Goodhart 2017). Whatever is driving these spatial patterns, a growing point of convergence across this literature is that important determinants operate at the level of geographically specific areas and not just individuals (Broz, Frieden, and Weymouth 2020).

Two sets of explanations have emerged to explain these geographic patterns. One strand of research highlights how economic shocks triggered by globalization have asymmetrically affected some regions within countries more than others. For example, Autor, Dorn, and Hanson (2013), and Autor et al. (2016) demonstrate that American local labor markets that experienced higher unemployment due to China-related trade shocks were also regions that showed greater support for Donald Trump in 2016. Similar patterns have been on display in Europe where radical right support (Colantone and Stanig 2018b) and Euroskepticism in the United Kingdom are disproportionately found in regions harder hit by China imports (Colantone and Stanig 2018a).

Additional work by Broz, Frieden, and Weymouth (2020) highlights how long-term de-industrialization-more advanced in some locations within countries than othershas had downstream effects on labor force participation rates, youth out-migration, declining property values, local tax revenue shortfalls, and even the prevalence of the opioid epidemic and public health outcomes. And, communities marked with these conditions show higher support for populist right-wing parties. Relatedly Cremaschi et al. (2022) show that the decline of public service in rural regions increases support 
for the radical right.

But because the economic drivers of radical right voting are inherently intertwined with cultural developments, a second strand of literature has zeroed in on a different facet of this problem: the escalation of an urban-rural split in electoral politics. Rodden's (2019) evidence points to the sharp and growing partisan divide between rural regions and cities, suggesting that over the course of the twentieth century in many established democracies, economic development has not led to the decline of this geographic split but rather to its growth. Today, in the United States, population density is a stronger predictor of voting patterns than at the beginning of the twentieth century (Rodden 2019: 4). The drivers of this phenomenon are closely related to the economic developments described above. Technological change, the decline of manufacturing, and the rise of the knowledge economy all contribute.

But in these accounts focusing on the urban-rural divide, scholars have emphasized a variety of causal pathways linking geography to radical right support. One channel emphasized by Katherine Cramer's (2016) important ethnographic work on rural communities in the Midwest of the United States is that residents in rural communities experience resentment over rural communities' economic dislocation and political marginality vis-à-vis urban decision makers. Other work emphasizes the importance of a strong sense of place-based identities in the countryside (though not confined there) that also make populist appeals attractive (Munis 2020, 2021; Fitzgerald and Lawrence 2011; Fitzgerald 2018; Bolet 2021). A third channel linking the urban-rural divide to radical right voting is embedded in conflicting social values and associated political attitudes. According to Rodden (2019) for example, in dynamic knowledge-based cities in which high skill workers increasingly live, distinctively "cosmopolitan" values, lifestyles, and political preferences are found that sharply diverge from the less secular and more traditional values prevalent in the rural areas inhabited by lower-skilled workers who feel "left behind" by the global economy (see also Iversen and Soskice 2020).

One example of work that clarifies how a clash in social values rooted in the 
urban-rural divide is driving politics in advanced democracies in Europe is offered in Maxwell $(2019,2020)$, who highlights the contrast between positive attitudes towards immigration in large "cosmopolitan" cities and more negative attitudes in the "nationalist" countryside. Maxwell, more systematically than others, also attempts to sort out the sources of the attitudinal or "values" gap on this key issue that activates the radical right. He asks: Is the urban-rural divide on attitudes towards immigration contextual (i.e. something about living in cities makes people feel more positive about immigration)? Or is it compositional (i.e. something about the types of people who live in cities)? Maxwell's evidence supports the latter position. Using panel data in which he traces voters' residential mobility and social attitudes over time, he demonstrates that individuals moving to cities (i.e. context) do not directly become more cosmopolitan. Rather, preexisting attitude differences between urban and rural residents and self-sorting (i.e. composition) explain much of the urban-rural social values gap (see also Iversen and Soskice 2020). As a result, Maxwell concludes that his "main takeaway message" is that the geographical clustering of attitudes towards immigration is usefully conceptualized as a "second-order manifestation of deeper demographic and cultural divides" (Maxwell 2019: 473).

But, what exactly are these "deeper" cultural divides? And how do we study them? For example, are they best understood as the result of shared local identity and history, or rather are they the consequence of individual-level characteristics? Here is where we reach the limits of existing literature. Contemporary economic change and the growing urban-rural gap are clearly important drivers of the regional clustering of radical right voting in economically "left behind" regions. But this literature itself suggests there are also longer-standing historical-cultural divides that preceded recent economic developments that may continue independently to shape where the radical right clusters. Even if research engages with these ideas (e.g. Fitzgerald and Lawrence 2011; Fitzgerald 2018) it is not fully clear whether these factors operate at the individual or community level. Thus, the precise content of these cultural and historical divides-and how to study them empirically-has remained elusive. 


\section{Cultural divides between center and periphery}

One answer to the question of the source of these regional divides is suggested in the pioneering work of Lipset and Rokkan (1967), who argued that in the historical process of nation-state formation, a variety of political cleavages emerged to shape contemporary politics. One such important cleavage is the historical "center-periphery" division between the centralizing core that pursued the homogenizing project of nationbuilding and the culturally distinctive outlying areas of the nation-state that were peripheral to it. ${ }^{1}$

In this framework (Rokkan and Urwin 1983; Rokkan 2009; Hooghe and Marks 2016; Alonso and Fonseca 2012: 20-21), during state formation, citizens in historically peripheral regions often carried lower status cultural markers-such as language, the local dialect, religion, dress, and customs. These community-level attributes provided the raw materials for a collective self-perception of marginality vis-à-vis the larger national political community. Lipset and Rokkan (1967: 13) described these peripheral regions as "bastions of primordial local culture." In Eugen Weber's classic work on French state-building, Peasants into Frenchmen (1976: 67), for example, Parisian primary school inspectors and tax authorities as late as the early twentieth century viewed the periphery as a land of "savages," where civilization was absent and a "wealth of tongues" (i.e. regional dialects) hindered the operation of officialdom.

Indeed, the periphery in nation-states was usually defined by two features: their low social status within the nation-state and the prevalence of identifiable cultural markers such as dialect or nonstandard language that reinforced that status. In James Scott's account of state-building, for example, the state's efforts to make society “legible" were hindered by peripheral regions' linguistic diversity (Scott 1998; see also

${ }^{1}$ While existing research by Haffert (2021) focuses on the impact of the church-state divide, we isolate the impact of a different Rokkanian cleavage (center-periphery), which has not received sufficient attention to date. We engage with Haffert (2021) in more detail in section A.1 in the appendix. 
Gellner 1993). Further, these regions were targets of what David Laitin has called state-directed "language rationalization" efforts (Laitin 1992: 10-14) and that Michael Hechter has more pointedly described as “internal colonialism” (Hechter 1972)-a process of subjugation and standardization of cultural differences that aimed at stamping out nonstandard regional languages (Hechter 1972: 191-205).

In this sense, "peripherality" is a community-level variable. Nonetheless, empirically its effects should play out and influence individuals living in the periphery. Citizens in such locations in the past and today believe they suffered distributive injustices in terms of power, wealth, and prestige. This in turn prompted a "politics of cultural defense," (Lipset and Rokkan 1967: 12), shaping residents' perception of themselves, elites, and outsiders. Scholarship has contended that this center-periphery divide began to recede in salience in the middle of the twentieth century, but also that it can be activated-and some scholarship has shown-it has re-emerged in some settings in recent years as a salient political cleavage (Alonso and Fonseca 2012), in part explaining the emergence of regional political parties across Europe.

There are empirical and theoretical reasons to believe that the lower self-perceived status of citizens in these historically and culturally fringe regions-Rokkan's "periphery"-can be enduring, which leads to support for anti-establishment and anti-immigrant radical right political parties today. First, an extensive literature in sociolinguistics finds that regional dialects are more persistent than modernization theory might predict (Edwards 2013: 69) and that speakers of historically low-status dialects-again, especially low-status regional dialects-continue to suffer discrimination in housing, employment, wages, and negative evaluations in terms of perceived prestige, skill, trustworthiness, and education (Edwards 2009; Segrest Purkiss et al. 2006; Purnell, Idsardi, and Baugh 1999; Du Bois 2019: 93). While dialect may not always connote lower status, it has been repeatedly demonstrated that in the German setting speakers of nonstandard regional dialects still suffer prejudice in housing and labor markets (Rakić, Steffens, and Mummendey 2011) and actually suffer a "wage penalty" when compared to speakers of standard Germany (Grogger, Steinmayr, and 
Winter 2020). This status of peripherality or "marginality"-especially if is still subjectively felt by residents of these regions today-may make people susceptible to appeals from political parties that challenge "central" elites and the political establishment.

In addition, scholarship has demonstrated that at the individual level, lower social status generates support not only for anti-establishment parties but also for radical right anti-immigrant political parties (Gidron and Hall 2017; Kurer 2020). As a literature in psychology clarifies, status threats, especially when coupled with even weak cultural markers (like dialect) can provoke strong out-group hostility (Tajfel, Billig, and Bundy 1971; Tajfel 1978; Enos 2014; Kustov 2020). Given these findings, we expect that residents in what amounts to low-status regions will have a propensity to vote for challenger and radical right populist parties via two additional mechanisms: antielite sentiment (having experienced a history of exclusionary policies) and hostility towards outsiders, including refugees and immigrants.

Finally, we then also expect that this pattern becomes stronger in moments in which the perception of "cultural threats"-such as the large influx of refugees-emerges. The key mechanism behind this is that the perceived "uncontrolled" influx of refugees activates and further intensives feelings of lower status and outgroup hatred, as well resentment of political elites-the individual-level mechanisms of our macro-level argument. Existing research demonstrates how "contact" can provoke anti-immigration reaction (Enos 2014). Additionally, during the so-called "refugee crisis" the public debate centered on elite failure (Harteveld et al. 2018; Mushaben 2020). Thus if populist radical right parties frame the influx of refugees as such a cultural threat-as the AfD did during the influx of refugees starting in 2015-one can expect this triggering effect to take hold. Similar arguments have been proposed and developed elsewhere for the German case during the so-called "refugee crisis" (Cantoni, Hagemeister, and Mark 2017; Choi, Poertner, and Sambanis 2019). 


\section{Data}

How can we study these cultural divisions, and how do we get an empirical grip on the historical center-periphery divide? We focus on one characteristic of localities we elaborated in our theoretical discussion above: language, more precisely dialects. A dialect is a subvariety of a language that differs from other subvarieties along three dimensions: vocabulary, grammar, and pronunciation (Edwards 2009: 63). Our strategy is to measure the strength of a dialect in a given region. As we have noted, the state-building and political development literature makes clear that a strong regional dialect that departs from the standard variant of a language is a key descriptive characteristic of the historical periphery (Weber 1976; Rokkan and Urwin 1983). Based on further research in sociolinguistics, we know that nonstandard dialects are enduring and remain a source of a variety of social identities (including place-based identity) and can also provide cultural markers that citizens continue to use to evaluate each other's origins and capabilities (Labov 1963; Remlinger 2009, 2017).

We employ two data sources to measure how distant a given regional dialect is compared to standard German. One of them is based on contemporary data collected by the German magazine Der Spiegel (see: Elspaß et al. 2018; Leemann, Derungs, and Elspaß 2019), while the second relies on a linguistic survey of about 40,000 schools in the late $19^{\text {th }}$ century (Lameli et al. 2014). We use the contemporary dialect data as a proxy for regions that were in the historical periphery in our main analyses. The historical data serves as evidence for the validity of the contemporary dialect data.

\subsection{Contemporary dialectal data}

The most comprehensive mapping of current regional German dialects is a unique online survey conducted by the German magazine Der Spiegel (see Elspaß et al. 2018). In 2015, Der Spiegel created a publicly accessible dialect quiz, where individuals answer 
a number of questions related to regional differences in dialect. ${ }^{2}$ Quiz respondents are shown a description of a verb, noun or adjective. They are then asked to select the regional version of the word from a list of choices that they use. An example is a question on the informal version of the verb 'to chat': In East Germany, the majority of respondents use 'quatschen', speakers closer to the North-Western coast employ 'schnacken' and Bavarians use 'ratschen'3. In total, respondents answer 24 questions, each aimed at the regional version of a specific noun, verb or adjective. Importantly, these 24 questions relate to differences in pronunciation, grammar, and vocabulary, and therefore capture all relevant dimensions of what constitutes a dialect. While the quiz was not created for strictly social scientific purposes, the 24 questions are directly based on a prior linguistic research project aimed at describing regional differences in German dialects, the Atlas der Deutschen Alltagssprache ("Atlas of Colloquial German", see Elspaß 2005).

After completing the quiz, a predictive algorithm estimates the region where the person is from. Finally, respondents are asked to evaluate the accuracy of the prediction and can enter their hometown. ${ }^{4}$ About two-thirds of all respondents enter

${ }^{2}$ The questions of the quiz itself is no longer available online. However, a related article can be found at https://www.spiegel.de/wissenschaft/mensch/dialekte-quizwo-spricht-man-so-wie-sie-a-1030362.html. Our data spans the period from April 2015 - June 2019, when we received the data. We have no information on the date of each quiz response.

${ }^{3}$ The Spiegel quiz is partially based on a similar quiz created by the New York Times. In the American context, an example of a regional lexical difference is the use of the words 'pop' and 'soda' to refer to a sweetened carbonated drink.

4We expect that respondents will usually indicate the place where they grew up rather than their current place of residence if the two are not the same. We base this assumption on the design of the online quiz and research that is based on the quiz we discuss this in more detail in Section A.9 in the appendix. 
their hometown, allowing us to trace responses to a specific location. In total, about 725,000 respondents indicate where they are from. We use this information to create a county-level measure of dialectal distance between a given county and region of Hannover, the area that is most strongly associated with standard German (for more elaboration on standard German and its relation to the Hannover dialect, see Mills 1985: 142; Polenz 2009: 123). Given the large sample, the number of respondents in each county is high. As we show in Figure A.1 in the Appendix, the majority of counties have more than 1,000 respondents. In a first step, we obtain the most common (modal) answer in each county for each of the 24 dialect questions that are part of the Spiegel quiz. For each county $i$, the modal answer to quiz item $k$ takes on the value $X_{i}^{k}$. In the following, we will refer to the modal answer in each county as a countyspecific dialect characteristic. Depending on the dialect characteristic, $X_{i}^{k}$ can take between 2 and 24 different values. In standard German, the $k^{\text {th }}$ dialect characteristic takes on the value $X_{\text {Standard German }}^{k}$. We define the distance between a given regional dialect and standard German as follows:

$$
d_{i}=24-\sum_{k=1}^{24} 1\left(X_{i}^{k}=X_{\text {Standard German }}^{k}\right)
$$

The sum on the right-hand side counts the number of times a region shares a dialect characteristic with standard German, which can be at most 24 . We then reverse this measure such that $d_{i}$ measures dialectal distance between a given county and standard German. It can range from o (a dialect that is equal to standard German) to 24 (shares no characteristics with standard German). We chose this measure of dialectal distance in accordance with prior work on the effect of dialects, chiefly Falck et al. (2012), who use the same definition of distance in conjunction with the $19^{\text {th }}$-century data described in Section 4.2.

A potential drawback of our method is that it requires dialect characteristics to be exactly the same to count towards the distance measure. To ensure that the results are not driven by our choice of the dialectal distance measure, we also calculate the dialectal distance using the average Jaro-Winkler distance between the prototypical 
characteristics. The Jaro-Winkler distance accounts for cases when dialect characteristics are similar, but not exactly the same (for more details see Cohen et al. 2003). The two measures are highly correlated, and our main results are similar across the two dialectal distance measures.

In Figure 1, we present the county-level distance from standard German across

Figure 1: Dialectal distance from standard German by county

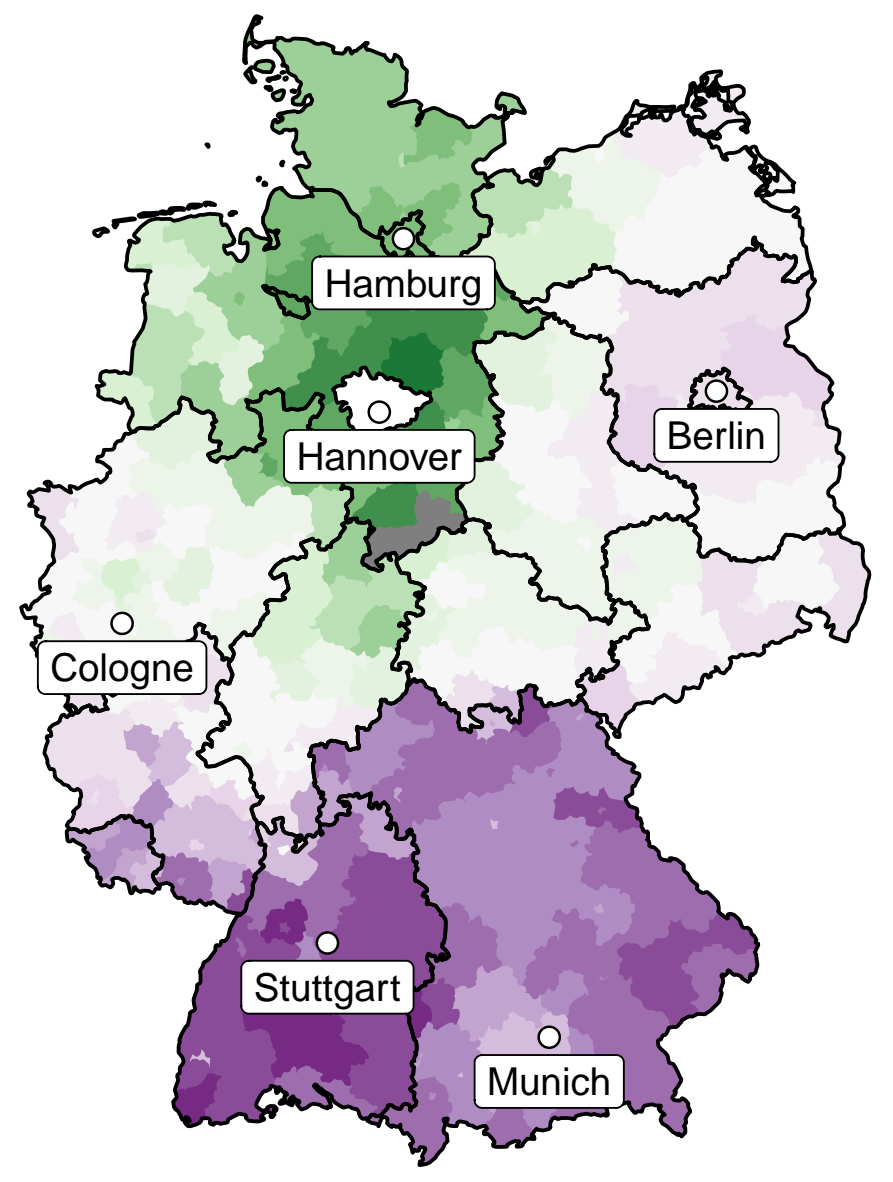

Distance from standard German

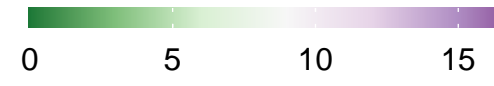

Note: Greater values indicate that the local dialect is more distant from standard German. The region shaded in white in the Northern central part of the country is Hannover, the region that most closely approximates standard German. The map also includes locations of major German cities, including Hannover. State borders are indicated in black. Counties shaded in grey are counties for which data is missing.

Germany. Unsurprisingly, the counties surrounding the Hannover region (shaded in 
white) are most similar to standard German. We also observe a pronounced NorthSouth divide: Southern German dialects are markedly more different from standard German than in the Northern part of the country. The two Southernmost states, Bavaria and Baden-Wuerttemberg exhibit the greatest distance to standard German.

Through the use of a supplementary data set on individual-level dialect use, we corroborate that our aggregate measure broadly corresponds to individual patterns of dialect use (we describe this data in more detail in Section A.8 in the appendix). We find that self-reported dialect usage is much more common in areas that are more distant from standard German, using our aggregate measure. We can therefore confirm that individuals are likely aware of the aggregate-level dialectal distance, as individuals in distant regions (as measured by our aggregate variable) and are much more likely to know and use dialects.

Figure 1 suggests that physical distance to Hannover, as well as North-South or East-West divides, are correlated with dialectal distance. We address this directly by including state fixed effects in all our specifications. The fixed effects ensure that we only compare differences in dialectal distance within federal states, rather than across states. This ensures that our results are not driven by East-West or NorthSouth divides. What is more, we also control for the physical distance between counties and their respective state capitals. Finally, we present additional robustness checks (see section 7 and Table A.11) to show that controlling for physical distance to the German border or to Hannover itself does not change our substantive conclusions. We note that the correlation between aggregate-level dialectal distance and population density is very close to zero (it is -0.06), indicating that the centerperiphery divide is not simply reducible to the urban-rural divide. In conjunction, these steps ensure that our dialectal distance variable does not simply pick up on urban-rural divides or geographic peripherality.

In a supplementary analysis in the appendix, we examine potential correlates of dialectal distance, based on survey and aggregate-level data (see section A.4). We observe that stronger dialects correlate with lower integration into surrounding areas, 
greater social engagement in the community, increased skepticism towards outsiders, and stronger suspicion of elites. Generally, these patterns corroborate that dialectal distance is indicative of center-periphery divides.

\subsection{Historical dialectal data}

As a secondary data source, we use historical dialectal data from the Deutscher Sprachatlas ('Atlas of the German Language', see Falck et al. 2012; Lameli et al. 2014), a survey conducted in the late $19^{\text {th }}$ century. This data allows us to validate the contemporary dialect data. In addition, the data serves as a closer approximation for historical patterns of the center-periphery divide, as it was measured prior to the turbulent $20^{\text {th }}$ century.

To create the Deutscher Sprachatlas, the linguist Georg Wenker surveyed over 40,000 elementary schools across the German Empire, asking students and teachers to translate 40 German sentences into their local dialects. Akin to the 24 dialect characteristics in the Der Spiegel data, Wenker's successor Ferdinand Wrede used Wenker's surveys to identify 66 'prototypical characteristics' of the German language. Much like the 24 characteristics in the Leemann, Derungs, and Elspaß (2019) data, we can use those 66 characteristics to construct a $19^{\text {th }}$-century distance measure between county-level dialects and standard German. ${ }^{5}$

Before turning to our main results, we use the historical dialectal data to validate our contemporary measure. We emphasize that the contemporary measure, while based on linguistic research (Elspaß 2005), was intended to serve mainly journalistic purposes. In contrast, the historical measure was the result of one of the most significant linguistic surveys ever conducted (Lameli et al. 2014). To ensure the quality of the data collected through the Der Spiegel online survey, we examine the correlation between the contemporary and the historical dialectal distance. While we expect that dialects change over time, they will likely not diverge completely. Indeed, the corre-

${ }^{5}$ We elaborate more on the details of the Wenker data in Section A.10 in the Appendix. 


\section{Empirical strategy}

lation between the $19^{\text {th }}$-century Wenker data and the Spiegel quiz data is 0.84 . We visualize the relationship between the two measures in Figure A.2 in the Appendix. The high correlation confirms that the contemporary dialectal distance indeed picks up on variation in dialects as measured in prior linguistic research.

\section{Empirical strategy}

Our empirical strategy proceeds in three steps, relying on aggregate as well as individual-level data. First, we assess the relationship between dialectal distance and county-level AfD support in the 2017 general election. ${ }^{6}$ These models include a number of relevant covariates as well as fixed effects to account for unexplained regional heterogeneity. We focus on potential confounders that have previously been shown to predict voting for radical-right parties, including population density, socioeconomic indicators and distance to the border.

Second, we complement the aggregate-level elections results with individual-level data from the German Longitudinal Election Study (GLES). In contrast to the aggregatelevel analysis, the GLES data allows us to control for a set of key alternative explanations on the individual-level, such as socio-economic background, education, nationalism and local attachment. The outcomes we use are a binary measure of AfD vote intentions as well as an 11-point AfD likability scale. ${ }^{7}$ Given the high frequency

${ }^{6} 2017$ is the first year that the AfD ran on an explicit anti-immigration platform. Between 2013 and 2017 the party significantly changed its personal - getting rid of the mostly Eurosceptic but not radical right leader Lucke and replacing it with the antimigration, more right wing colleague Petry - and its platform as carefully laid out and empirical shown in (Cantoni, Hagemeister, and Mark 2017: 28-29). In Table A.6 in the appendix, we also present results for the 2013 and 2021 elections. In the 2013 general election, the AfD was most strongly associated with Eurosceptic and economics issues.

${ }^{7}$ We note that the GLES survey data covers all 299 electoral districts, i.e. it contains 


\section{Empirical strategy}

at which the data is observed-18 waves between 2013 and 2018-we can further use this data to study how the relationship between dialects and radical-right support varies over time.

Finally, we shed light on the mechanisms that underlie our proposed argument through additional analysis of survey data that measures perceived status, anti-elitism and anti-immigrant attitudes. The goal of this final exercise is to provide support for the individual-level mechanisms that animate our macro-level argument.

Throughout the results section, we estimate a set of linear models that can be described as follows:

$$
y_{i, j}=\alpha+\gamma_{j}+\tau d_{i, j}+\beta^{\prime} X_{i, j}+\varepsilon_{i, j}
$$

Here, $y_{i, j}$ is the outcome of interest for unit $i$ in-state $j$, which is either radical-right voting or individual attitudes. Our main independent variable is $d_{i, j}$, the dialectal distance between a given county $i$ and standard German. We always standardize $d_{i, j}$ such that coefficients can be interpreted as the effect of a one standard deviation increase in dialectal distance. We also include a vector of covariates $X_{i, j}$ as well as state fixed effects $\gamma_{j}{ }^{8}$ For all county-level models, we control for regional GDP/capita, average wages, population density, unemployment rates, total population, \% Catholic, the share of commuters, the physical distance to the state capital, and the CDU/CSU vote share in the 2013 general election. We provide summary statistics for all outcomes and explanatory variables in Table A.1 in the Appendix.

We concede that causal identification is difficult in the context of our research question. We rely on the assumption that dialectal distance is independent of the

respondents from all 299 electoral districts.

${ }^{8}$ The notation we use refers to counties, which form the basis for our main result. For counties, the level of observation is the same as the level at which dialectal distance is measured. Given the structure of the GLES data, the dialectal distance for survey analyses is measured at the level of the electoral district - survey respondents are nested within districts. 


\section{Results}

potential electoral outcomes, conditional on county covariates and fixed effects. The strongest threat to identification is omitted variable bias, namely that unobserved factors drive our findings. In a series of robustness checks, we address confounding through additional control variables, more fine-grained geographical fixed effects, a design-based weighting approach as well as a sensitivity analysis. We particularly highlight the results of the sensitivity analysis. We demonstrate, even if there was an unobserved confounder with a partial correlation that is twice as strong as the one between the unemployment rate and AfD support, its inclusion would not change our substantive conclusions. Given that we control for a host of relevant explanatory factors, the existence of an unobserved confounder of this magnitude appears extremely unlikely. As we elaborate in section 7, the additional analyses thus leave us with little reason to believe that our results are driven by unobserved confounding.

\section{Results}

\subsection{Aggregate electoral results}

In Table 1, we demonstrate that there is a significant and positive association between dialectal distance from standard German and the electoral success of the AfD. Depending on the specification, a one standard deviation increase in distance from standard German is associated with a 0.78-1.17 percentage point decrease in the voting for the AfD. The observed effect corresponds to a decrease of about 0.2 standard deviations in AfD voting, confirming that dialectal distance is a substantively meaningful correlate of radical-right voting. This relationship holds both when comparing across German states (model 1, no state fixed effects) and within states (model 2, including state fixed effects).

Crucially, controls for population density, commuting, and distance to state capitals ensure that we are not simply picking up on urban-rural divides. What is more, we account for time-invariant regional differences by including state fixed effects. After including fixed effects, the remaining variation in dialectal distance stems solely 
from within-state differences. Therefore, our model implies comparisons between, for example, counties with stronger and weaker dialects within Bavaria, but never between Bavaria and Saxony. State fixed effects ensure that our results are not confounded by (i) physical distance to Hannover, (ii) differences between West Germany and the territory of the former German Democratic Republic and (iii) differences between Southern and Northern Germany. To alleviate further concerns about geographic confounders, we present additional specifications that control for the physical distance to the German border and Hannover in Table A.11 in the appendix.

In a supplemental analysis in Table A.7 in the appendix, we show that stronger dialects are negatively correlated with electoral support for the Green party, while we do not find significant estimates for the other major German parties. The fact that stronger dialects correlate with AfD gains and Green party losses appears sensible, as these parties hold opposing views along a number of relevant policy areas. We further assess the relationship between dialectal distance and AfD support in the 2013 and 2021 elections in Table A.6 in the appendix. We find no results in 2013, which is consistent with the activation mechanism which we describe in more detail in Section 6.2. For the recent 2021 election, we find very similar results to 2017.

In the next step, we examine the relationship between the $19^{\text {th }}$-century dialect data and radical-right voting in models 3 and 4 . We find comparable results, both in terms of direction and magnitude. ${ }^{9}$ The fact that results are similar using the $19^{\text {th }}$ century data is reassuring, as it may be better suited to pick up on historical centerperiphery divides. Taken together, the results suggest that dialectal distance is a significant and substantially meaningful predictor of radical-right voting.

Given its history as a divided country, patterns of radical-right voting differ between East and West Germany. Since the fall of the Berlin Wall in 1989, the East has voted in higher numbers for radical right parties-such as the 'Nationaldemokratis-

${ }^{9}$ We stress that all covariates and the state boundaries used for the fixed effects are post-treatment with respect to the historical dialectal distance measure. Therefore, the results in model 4 should be treated with caution. 
Table 1: Effects of dialectal distance on radical right voting in 2017.

\begin{tabular}{|c|c|c|c|c|}
\hline & \multicolumn{4}{|c|}{ DV: AfD vote share, 2017} \\
\hline & \multicolumn{2}{|c|}{ Contemporary data } & \multicolumn{2}{|c|}{ Historical data } \\
\hline & (1) & (2) & (3) & (4) \\
\hline Dialectal distance & $\begin{array}{c}0.778^{* * *} \\
(0.264)\end{array}$ & $\begin{array}{l}1.172^{* * *} \\
(0.354)\end{array}$ & $\begin{array}{c}0.898^{* * *} \\
(0.188)\end{array}$ & $\begin{array}{l}0.478^{* *} \\
(0.230)\end{array}$ \\
\hline Mean of DV & 13.39 & 13.33 & 13.4 & 13.34 \\
\hline $\mathrm{N}$ & 400 & 392 & 399 & 391 \\
\hline $\mathrm{R}^{2}$ & 0.021 & 0.828 & 0.028 & 0.810 \\
\hline State FE & & $\checkmark$ & & $\checkmark$ \\
\hline Covariates & & $\checkmark$ & & $\checkmark$ \\
\hline
\end{tabular}

che Partei Deutschlands (NPD)' and the 'Republikaner'-and a similar pattern holds true for the AfD. This might suggest that the relationship between dialectal distance and AfD voting is particularly strong in East Germany. However, as we show in the Appendix Table A.8 this is not the case. Splitting the sample into East and West shows that the association between dialectal distance and AfD voting holds in both parts of the country, although the effects are imprecise given the lower sample size in East Germany.

\subsection{Individual-level results}

We now examine the relationship between dialectal distance and political preferences on the individual-level. We begin with panel evidence of the German Longitudinal Election Survey (GLES, see Schmitt-Beck et al. 2010). We use the survey data to complement the aggregate electoral results discussed in the previous section. We reiterate that our core theoretical argument works at the community level. However, our argument has implications at the individual-level, since it speaks to individual-level voting decisions. What is more, the individual-level analysis allows us to account for key alternative explanations unaccounted for in the aggregate analysis. For instance, 
we can control for individual-level factors heavily debated in previous research on the radical right such as nationalistic attitudes (Rydgren 2008), local attachment (Fitzgerald 2018) and various other factors potentially accounting for the observed correlation between dialectal distance and voting for the radical right. A second advantage is that there are 18 panel waves between 2013 and 2018. This allows us to gauge whether place-based identities were 'activated' as communities experienced an unprecedented influx of outsiders during the 2010 s "refugee crisis".

The GLES survey includes information on the electoral districts where respondents reside. Accordingly, we aggregate the Elspaß et al. (2018) dialect quiz responses to the level of the electoral districts. There are 299 electoral districts in Germany, which means that each district contains, on average, about 1.3 counties. Aside from the changing level of aggregation, the definition of the dialectal distance measure remains the same as discussed in section 4.1. From the GLES, we select (1) one item asking about vote intentions in the next general election and (2) an item that asks respondents to report positive or negative feelings towards the AfD party. The vote intention items simply ask respondents to indicate their most likely vote choice for both the district candidate and the party vote choice in the next general elections. ${ }^{10}$ The party attitude item asks respondents to rate the AfD party on an 11-point scale. ${ }^{11}$ In a first step, we pool 18 GLES waves between June 2013 and March 2018. We then estimate the effect of dialectal distance on individual vote intentions and attitudes towards the AfD party.

We present the results from the pooled sample in Table 2. Across 18 waves of the GLES, we find that dialectal distance predicts an increase in the likelihood to vote for

\footnotetext{
${ }^{10}$ Below, we focus only on the party choice. The effects are similar in size and significance for the candidate vote choice.
}

${ }^{11}$ The exact wording is "Was halten Sie so ganz allgemein von [der Afd]?", which translates to "What do you think of / what is your attitude towards the AfD party". Respondents answer on an 11-point scale, ranging from very negative to very positive. 


\section{Results}

the AfD party. Likewise, respondents are more likely to rate the AfD favorably when dialects in their electoral district are stronger. We control for respondents' gender, age, education, employment status, income, the urbanity of their location, and separately also for their self-rated nationalism. The addition of the controls addresses the possibility that aggregate-level dialects are a mere proxy for individual-level characteristics. If our results were driven by the fact that more linguistically distant places are composed of low-income or low-education individuals, then we would not find results after conditioning on these individual-level variables. ${ }^{12}$ The results in Table 2 are statistically different from zero and mirror the findings in section 6.1, where we document similar patterns on the aggregate level.

We emphasize that our conclusions remain unchanged when we control for a key alternative explanation: nationalist attitudes. In two GLES waves, respondents are asked to share their opinion on three items relating to nationalistic ideology. To form a composite scale of nationalism, we sum those three items. ${ }^{13}$ By controlling for nationalism among the GLES respondents, we verify that we are not merely picking up on nationalist attitudes. Our results remain substantively meaningful even when we condition on nationalism. Similarly, the correlation between dialectal distance and voting for the AfD remains significant if we control for local attachment - a factor

${ }^{12}$ We present an extended version of this Table that includes covariate coefficients in Section A.7.3 in the appendix. In Table A.5 in the appendix, we present correlations between the variables.

${ }^{13}$ The index is a 15 point scale based on three questions. The questions are: (1) "how important is being German for your identity", (2) "how likely are you to use the word 'we' versus 'they' when speaking of the German people" and (3) "how well does the adjective 'German' suit you?" Each item allows respondents to pick from five answer categories, each measuring different levels of agreement with the survey question. As a result, our composite index ranges from one to fifteen, with greater values indicating higher degrees of nationalism 
well established to predict radical right voting outside of Germany (Fitzgerald 2018).14

Table 2: Effects of dialectal distance on radical right voting intentions and likability.

\begin{tabular}{|c|c|c|c|c|c|c|}
\hline & \multicolumn{3}{|c|}{ AfD vote intentions } & \multicolumn{3}{|c|}{ AfD scalometer } \\
\hline & \multicolumn{3}{|c|}{ Party vote } & \multicolumn{3}{|c|}{ Range: $1-11$} \\
\hline & $(1)$ & $(2)$ & (3) & $(4)$ & (5) & (6) \\
\hline Dialectal distance & $\begin{array}{l}0.008^{* *} \\
(0.004)\end{array}$ & $\begin{array}{l}0.016^{* *} \\
(0.007)\end{array}$ & $\begin{array}{l}0.009^{*} \\
(0.005)\end{array}$ & $\begin{array}{l}0.141^{* * * *} \\
(0.047)\end{array}$ & $\begin{array}{l}0.157^{* * *} \\
(0.060)\end{array}$ & $\begin{array}{l}0.130^{* *} \\
(0.051)\end{array}$ \\
\hline Nationalism scale (1-5) & & $\begin{array}{c}0.066^{* * *} \\
(0.007)\end{array}$ & & & $\begin{array}{l}0.781^{* * *} \\
(0.061)\end{array}$ & \\
\hline Local attachment (1-5) & & & $\begin{array}{c}-0.004 \\
(0.006)\end{array}$ & & & $\begin{array}{l}-0.054 \\
(0.055)\end{array}$ \\
\hline National attachment (1-5) & & & $\begin{array}{l}-0.003 \\
(0.007)\end{array}$ & & & $\begin{array}{c}0.072 \\
(0.063)\end{array}$ \\
\hline Mean of DV & 0.09 & 0.14 & 0.09 & 3.32 & 2.94 & 3.22 \\
\hline$N$ & 26841 & 3414 & 4975 & 33104 & 3581 & 5265 \\
\hline Unique respondents & 2061 & 1992 & 2012 & 2089 & 2065 & 2073 \\
\hline$R^{2}$ & 0.02 & 0.07 & 0.03 & 0.05 & 0.12 & 0.06 \\
\hline East-West FE & $\checkmark$ & $\checkmark$ & $\checkmark$ & $\checkmark$ & $\checkmark$ & $\checkmark$ \\
\hline Covariates & $\checkmark$ & $\checkmark$ & $\checkmark$ & $\checkmark$ & $\checkmark$ & $\checkmark$ \\
\hline
\end{tabular}

Notes: The tables contains coefficient estimates from 9 linear models. The first three models predict the AfD vote intentions for party votes in the AfD in the next general election. The final three models predict positive attitudes towards the AfD party. The main independent variable is dialectal distance to standard German, aggregated to the level of electoral districts. We pool 18 waves of the German Longitudinal Election Study (GLES). Standard errors, clustered by respondent, are shown in parentheses. The covariates are respondent gender, age, education, employment status, income, nationalistic attitudes and urbanity of the place of residence. We present an extended version of this table, which includes covariate coefficients, in Section A.7.3 in the appendix. We further present an alternative specification that uses voting for any radical right party as the outcome in Section A.7.4 in the appendix. ${ }^{* * *} p<.01 ;{ }^{* *} p<.05 ;{ }^{*} p<.1$

Finally, we utilize the panel structure of the GLES data to better understand how the correlation between dialectal distance and favorable attitudes towards the AfD varies across time. We focus on a pivotal time period in recent German history, the German refugees crisis. Instead of pooling all 18 waves, we estimate model 3 from Table 2 separately for each GLES wave. In Figure 2, we report the association between dialectal distance to standard German and favorable attitudes towards the AfD party,

${ }^{14}$ We elaborate more on the distinctions between nationalism and national attachment in the final paragraph of Section A.2.2 in the appendix. 
across all 18 waves.

Figure 2: Effects of standardized dialectal distance on AfD likability scale over time.

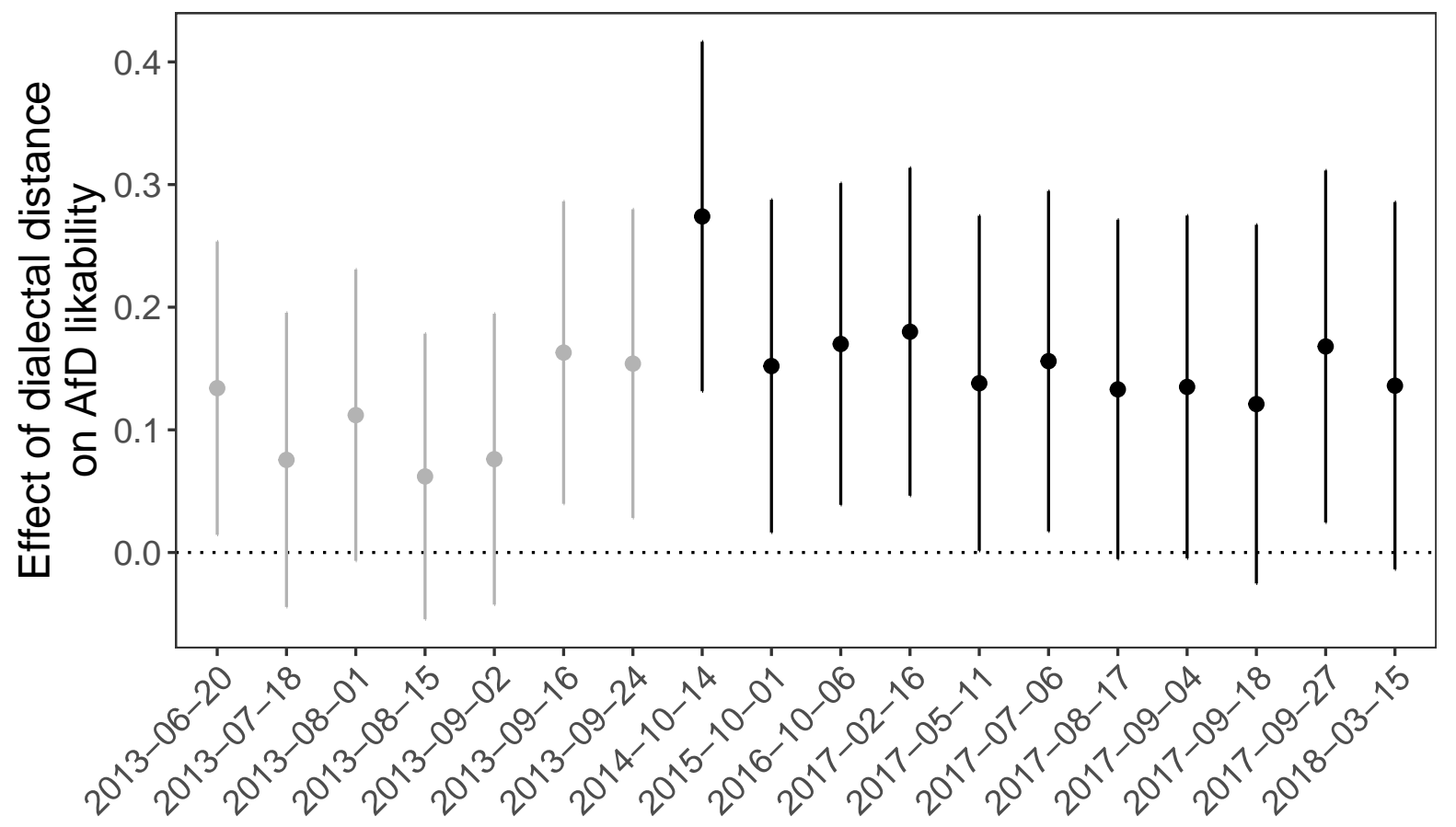

$\rightarrow$ During the refugee crisis $\longrightarrow$ Prior to the refugee crisis

Note: We plot coefficients and $95 \%$ confidence intervals from models estimated separately for each GLES wave. On the $x$-axis, we indicate the first day of data collection for each wave. The models follow the specification in model 5 in Table 2.

We find suggestive evidence for a stronger correlation between dialectal distance and favorable attitudes towards the AfD as the refugee crisis becomes more salient. This is consistent with a broader literature that shows that latent resentments can be activated with direct contact with perceived "outsiders" such as migrants (Enos 2014; Choi, Poertner, and Sambanis 2019). In 2013, political elites and the media did not heavily engage with questions of migration, the term "refugee crisis" was not yet topical at the time. In our results, we find that the effect of dialectal distance in 2015 is more than twice as large as in 2013. ${ }^{15}$ The first public reports about a large influx of refugees to Europe and Germany started in 2014 when the number of asylum-seekers

${ }^{15}$ To formally test this, we run an interaction model with a dummy variable indicating the waves surveyed prior (up until wave 7) and during the "refugee crisis". We find a 


\section{Results}

started to increase significantly in comparison to 2013 with 627,000 people seeking asylum across Europe. Thus, the findings we report here can be read as suggestive evidence in line with the mechanism that the increase in "outsiders" and the perception of crisis leads to a stronger relationship between place-based identity and voting for radical-right parties. In addition, we note that refugees in Germany are assigned to counties in proportion to county population. Therefore, there is no meaningful variation in actual exposure to refugees across counties. In contrast, our results suggest that perceptions of the influx differentially activated support for the radical right across regions.

Our final piece of individual-level evidence is an analysis that relies on self-reported measures of dialect knowledge and usage from the German Socio-Economic Panel Survey (SOEP), which were first used by Grogger, Steinmayr, and Winter (2020). We discuss the data, estimation and results in more detail in section A.8. We find there is no correlation between being able to speak a dialect and AfD support, but we do find that using a dialect in a work setting is correlated with greater AfD support. In other words, merely knowing a dialect is less important than using it every day in a formal setting, consistent with our interest in dialect as a broadly sociological, and not an individual-level phenomenon. Importantly, these associations are robust to controlling for education and socio-economic status as well as to an additional instrumental variables strategy. We note, however, that this data only covers $30 \%$ of all German counties, or about $44.7 \%$ of the German population. As a result, the geographic scope of the SOEP dialect data is smaller than that of the data we use for our main analyses. In addition, counties covered by the SOEP dialect data tend to be larger, more densely populated and have higher wages and GDP/capita (see also figure A.6 in the SI. Therefore, the results from this analysis are likely not directly

significant difference between the coefficients prior to the "refugee crisis" and the first wave during it. 
comparable to our main results discussed in section 6.1. ${ }^{16}$

\subsection{Micro-level mechanisms: lower subjective social status, anti-elitism, and outsider resentment}

Beyond the main effect of dialectal distance, our theoretical argument discussed three key individual-level mechanisms which facilitate voting for the radical right in peripheral communities: lower subjective social status, which should fuel anti-elitism and hostility towards outsiders - particularly migrants and refugees. In figure 3, we present associations between dialectal distance and a set of individual-level variables from the German Socio-Economic Panel (SOEP) and the GLES survey measuring these dimensions.

In the top panel, we report a correlation between our dialectal measure with subjective social status. Respondents in communities with stronger dialects are more likely to rank themselves lower if asked to place themselves on a social status or "social importance" ladder. Importantly, this subjective assessment holds even conditional on a variety of important objective measures of individual well-being such as income, education, or employment status (see section A.11 in the appendix for more information on the covariates).

Regarding anti-elitism, we find that respondents in peripheral communities are also significantly more likely to exhibit populist attitudes. ${ }^{17}$ This correlation is driven

${ }^{16}$ The individual-level dialect data and the IV strategy were first employed by Grogger, Steinmayr, and Winter (2020), who we follow in the construction of the instrument. We discuss this in more detail in Section A.8.

${ }^{17}$ The populism scale is a question battery consisting of eight questions with a 5-point response scale on a) politicians talk too much and do too little; b) normal people are linked by good and honest characters; c) the people should have the last say on important policy decisions; d) normal people work together for a common cause; e) the difference between people and elites are larger than differences within the 
Figure 3: Dialectal distance, self-perceived social status, anti-elitism, and out-group hostility

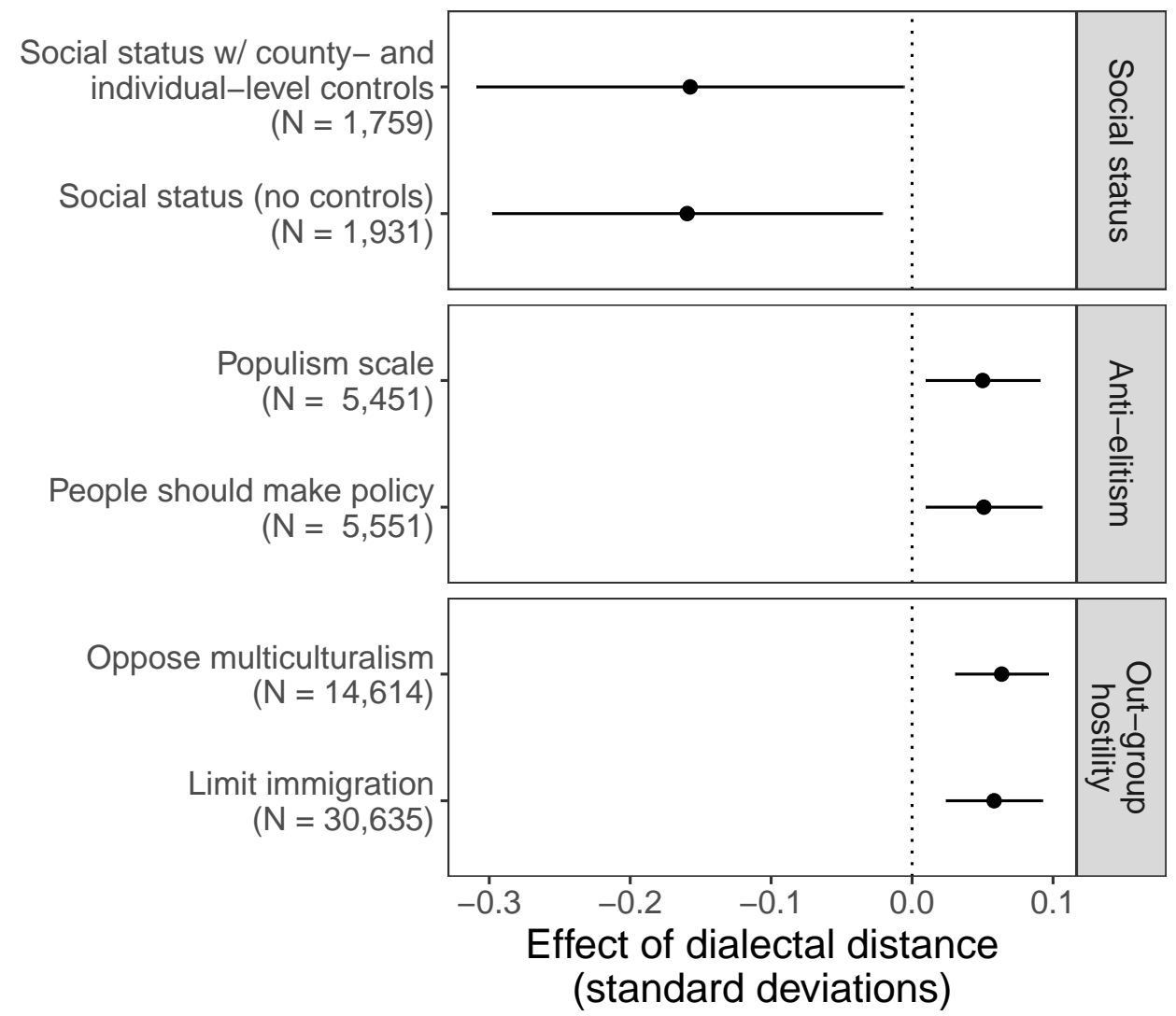

Note: We plot coefficients and 95\% confidence intervals from six models, where we estimate the association between standardized dialectal distance and standardized measures of self-perceived social status, anti-elitism, and out-group hostility. Outcomes and sample sizes are indicated on the yaxis. Self-perceived social status 2018 wave of the SOEP survey, while the other outcomes are taken from multiple pooled waves of the GLES survey. All outcomes are standardized, i.e. the coefficients are changes in standard deviation for a one standard deviation change in dialectal distance. The models for the elitism and hostility outcomes follow the specification in model 1 in Table 2. For more info on the social status outcome, the associated estimation, and control variables, see section A.11 in the appendix.

by the anti-elite dimension of the populist scale included in the GLES, more specifically by the claim that "people should make key policy decisions and not political elites".

Turning to attitudes towards outsiders, we observe that strong nonstandard dialects are associated with a rejection of multiculturalism as well as calls for limits to immigration. A one standard deviation increase in dialectal distance is associated people; f) people, not politicians should make most important policy decisions; $g$ ) parliamentarians should follow the will of the people; $h$ ) normal people share the same values and interests. 
with a 0.07 standard deviation increase in "support of stronger limits to immigration". We observe similar effects for opposition towards multiculturalism. Taken together, these findings are consistent with the proposed mechanisms the underlie the finding that peripheral regions are more supportive of the radical right AfD party.

\section{Robustness}

In addition to the main results, we conduct several additional checks to ensure that our results are not driven by unobserved confounding, idiosyncrasies in the sample, the choice of covariates, the model specification, or the operationalization of the outcome.

In a first step, we show that the results are robust to including two additional controls. To ensure that our measure of dialectal distance is not confounded by a history of nationalism or racism, we add an indicator for a history of pogroms in the 1920 ( (taken from Voigtländer and Voth 2012) and the NSDAP (Nazi party) vote share in 1933 as additional controls. In columns 2 and 3 in Table A.8 in the Appendix, we show that the effect size and significance remain unchanged when we include these controls.

Second, we demonstrate that our results are robust to an alternative operationalization of the outcome. As shown in section 4.1, our dialectal distance measure requires exact matches between characteristics of regional dialects and standard German. We relax this requirement in Table A.9. Here, we instead use the Jaro-Winkler distance, which takes into account words that are similar, but not exactly the same. ${ }^{18}$ We show that the choice of dialectal distance measure does not change our conclusions. Substantively, the effect sizes are similar to what we show in our main specification in Table 1.

${ }^{18}$ See Cohen et al. (2003) for a precise definition. As before, we calculate the distance for each of the 24 dialect characteristics and then average them, such that $d_{i}^{\mathrm{J}-\mathrm{W}}=$ $\frac{1}{24} \sum_{k=1}^{24} d^{\mathrm{J}-\mathrm{W}}\left(X_{i}^{k}, X_{\text {Standard German }}^{k}\right)$, where $d^{\mathrm{J}-\mathrm{W}}$ is the Jaro-Winkler distance. 
Third, we use additional controls and fixed effects to alleviate concerns of unobserved spatial confounders. First, we add fixed effects for Regierungsbezirke ("administrative districts"), the administrative level below federal states. ${ }^{19}$ While state fixed effects likely already account for a large degree of unobserved regional heterogeneity, the smaller administrative districts allow us to account for an even greater amount of spatial differences. As we show in Table A.10 in the Appendix, adding administrative district fixed effects does not change our substantive conclusions. Second, we present results from alternative specifications that control for (i) the physical distance to Hannover and (ii) the physical distance to the German border (see Table A.11 in the appendix). We again find that the main result remains unchanged.

Fourth, we use a bootstrap approach to examine whether our results are affected by uncertainty in the measurement of our dialectal distance variable. As mentioned before, the county-specific dialectal distance measure is based on a sample of dialect quiz respondents who are from the county in question. To incorporate measurement uncertainty, we re-sample from all quiz respondents and then calculate all countyspecific dialectal distances using the resulting 500 bootstrap samples. We then reestimate our main models for each bootstrap sample. In Section A.7.1 in the Appendix, we show that incorporating measurement uncertainty in this manner does not change our conclusions

Fifth, we address post-treatment bias through the use of the sequential-g estimator (see Homola, Pereira, and Tavits 2020: for an example in a similar setting). As stated before, the majority of our control variables are likely measured after 'treatment', i.e. after the development of local dialects. In Section A.7.2 in the Appendix, we demonstrate that our conclusions remain unchanged when accounting for posttreatment bias.

${ }^{19}$ The 'administrative district' unit only exists in the four large states of Bavaria, Northrhine-Westfalia, Hesse and Baden-Wuerttemberg. For all other states, the "administrative district" unit is not distinct from the federal state. Taken together, there are 31 administrative districts. 
Finally, we use an alternative, design-based approach to estimate treatment effects. In doing so, we rely on the covariate balancing propensity score for continuous treatments (see Imai and Ratkovic 2014) to (1) estimate a propensity score model for treatment assignment and (2) obtain covariate balancing weights. The propensity score uses all covariates and state fixed effects that we include in our main model. While the dialectal distance treatment remains correlated with some of the covariates, CBPS weighting greatly improves balance. In Section A.12 in the Appendix, we present the results. In the weighted models, the estimated effect of dialectal distance on AfD voting is comparable in magnitude and significance to our base models.

\subsection{Sensitivity to unobserved confounding}

As an alternative approach to address confounding, we implement an additional sensitivity analysis (Imbens 2003). Although we already control for several social, demographic, and economic variables, it is impossible to account for all possible confounders. One alternative approach would be to find a suitable instrument for our dialectal measures. Yet, finding an instrument that fulfills the exclusion restriction for dialectal distance - which has deep cultural and historical roots in communities - seems unlikely.

Instead, we implement a sensitivity analysis to gauge how strong an unobserved confounder would have to be to invalidate our findings (for a more in-depth discussion of such methods, see Imbens 2003). We implement the sensitivity using the method and package developed by Cinelli and Hazlett (2020). We use the main results from the second model in Table 1 as the baseline model for the sensitivity analysis.

In Figure 4, we present the results of the analysis. A point in the plot represents a hypothetical unobserved confounder. The $x$-coordinate represents the partial $R^{2}$ of the confounder with respect to the treatment (dialectal distance) and its y-coordinate represents the partial $R^{2}$ with respect to the outcome (radical right voting). For reference, we have included the partial $\mathrm{R}^{2}$ values for the unemployment rate as well as a hypothetical confounder that is twice as strong as the unemployment rate (see also 


\section{Robustness}

Figure 4: Sensitivity analysis

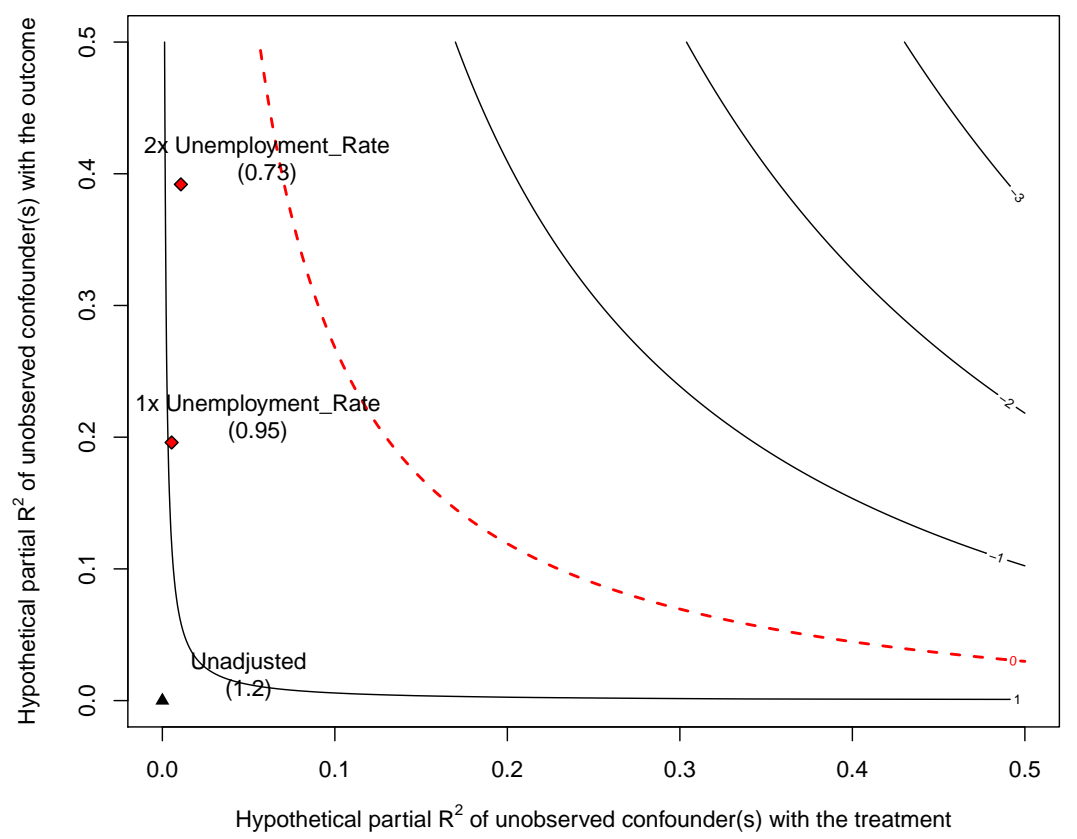

Notes: Results from the sensitivity analysis proposed by Cinelli and Hazlett (2020). The plot indicates how strongly confounders would have to be correlated with the treatment and the outcome to reduce the estimated effect size to zero (dashed red line). The original effect size from table 1 is shown in the bottom left corner - the scenario where there is no unmeasured confounding. The red diamond shape indicates partial correlations for unemployment rates and a hypothetical confounder that is twice as strong as the unemployment rate. The interpretation of figure is as follows: if we were to include a confounder as strong as the unemployment rate, the estimated effect size would drop to 0.95 . For a confounder that is twice as strong as the unemployment rate, the estimated effect of dialectal distance on radical right voting would drop to 0.73 .

table A.13 in the Appendix, where we show the same quantities for all covariates). The numbers shown next to the variable names in the plot indicate the effect size if an unobserved confounder with the same strength was included in the model. If we had failed to include a confounder that is as twice as strong as the unemployment rate -by far the strongest predictor in our models- the estimated effect size would drop to 0.73. To put it differently, even if there was an unmeasured confounder as twice as strong as the unemployment rate, adding it would not change the substantive conclusions of our paper. 


\section{Conclusion}

\section{Conclusion}

Recent scholarship has made great strides in understanding how individual-level characteristics shape the proclivity for supporting the radical right (Gidron and Hall 2017; Inglehart and Norris 2016; Hangartner et al. 2019). Recent work in political science has begun to give equivalent attention to the question of how the local communities where voters actually live, shape their predisposition to vote for the radical right (but see also: Fitzgerald and Lawrence 2011; Eliasoph 2017; Munis 2021; Bolet 2021). We seek to speak to this question by studying how deeper, historical centerperiphery dynamics voting for the radical right.

We argue that communities that were in the historical "periphery" during the center-periphery conflicts that shaped the formation of modern nation-states are more likely to vote for the radical right (Lipset and Rokkan 1967). This is so because being in the periphery of a nation-state gives rise to identifiable and enduring lower status markers such as diverging social norms and dialects - which also correlate today with lower self-ranking on a social status scale, anti-elite sentiment, and outgroup hostility. This persistent feeling of being "left behind" renders voters susceptible to anti-elite and anti-immigrant political party appeals.

Empirically, we approximate peripheral communities by using original data on dialects in Germany, based on a unique online dialect survey of 725,000 respondents and $a 19^{\text {th }}$ century linguistic survey. We then show that peripheral communities are indeed more likely to vote for the radical right - both on the aggregate as well as the individual level. We also demonstrate that this correlation is unlikely to be driven by omitted variable biases.

Before moving on, we highlight two empirical caveats of our analysis. Given the topic at hand, we cannot make use of a quasi-experimental or experimental strategy to assess the effect of aggregate-level dialectal distance. While our sensitivity analysis in Section 7.1 suggests that our results are unlikely to be driven by unobserved confounding, we nevertheless stress that our results are correlational in nature. Second, our main independent variable (dialectal distance) was not purposefully col- 


\section{Conclusion}

lected to measure county-level dialectal distance. For smaller counties, this may result in some measurement error, even though the total number of respondents is very large. We partially address this through a bootstrap approach in Section A.7.1 and through validation using the historical data in Section A.5 the appendix. Yet, but we cannot completely rule out that our aggregate dialectal distance indicator is subject to measurement error for small counties.

Our focus on how dialect reflects Lipset and Rokkan's (1967) classical cleavage between center and periphery represents a new perspective in the study of electoral behavior. A long-standing field of sociolinguistics has repeatedly demonstrated that speaking is more than a linguistic act; it is a social act and correlates with different patterns of self-presentation, and identification (Labov 1963). We have demonstrated that language can be political too. Given the enduring importance of regional dialects in many national settings around the world (Garrett 2010; Upton and Widdowson 2013: 200-224), the electoral consequences of location-specific dialects are a promising area of research.

This line of research, we believe, is relevant, furthermore, because one of the emerging dynamics within established democracies is the "return" of geography (Rodden 2019). The drivers of radical right populism, it has become clear, do not always unfold evenly across a country's territory but instead have a spatial component some locations are more prone to political radicalization than others (Charnysh and Peisakhin 2022; Charnysh and Finkel 2017; Patana 2020). Existing research has made clear the economic roots of this (Autor et al. 2016). Likewise, in established democracies, growing economic inequality, it has been argued, has activated the type of reactionary identity politics that fuels nativism and right-wing radicalism (Piketty 2020). Less appreciated, however, to date is how economic geography interacts with nonmaterial social patterns-local patterns of social identification, culture, and normsthat predispose certain communities to vote more for the radical right than others. As this paper has made clear, understanding the interaction of economic geography and these less-studied cultural attributes of local communities in cross-national per- 
spective remains a promising area for future research.

\section{References}

Acharya, Avidit, Matthew Blackwell, and Maya Sen. 2016. "The Political Legacy of American Slavery." Journal of Politics 78 (3): 621-641.

Alesina, Alberto, Paola Giuliano, and Nathan Nunn. 2013. "On the Origins of Gernder Roles: Women And The Plough." Quarterly Journal of Economics 128 (May): 469-530.

Alonso, Sonia, and Sara Claro da Fonseca. 2012. "Immigration, Left and Right." Party Politics 18 (6): 865-884.

Autor, David, David Dorn, Gordon Hanson, Kaveh Majlesi et al. 2016. "Importing political polarization? The electoral consequences of rising trade exposure." SSRN, https://papers.ssrn. com/sol3/papers. cfm?abstract_id=2840708.

Autor, David H, David Dorn, and Gordon H Hanson. 2013. "The China Syndrome: Local Labor Market Effects of Import Competition in the United The China Syndrome: Local Labor Market Effects of Import Competition in the United States*." American Economic Review 103 (6): 2121-2168.

Becker, Kara. 2009. “/r/and the construction of place identity on New York City's Lower East Side 1." Journal of Sociolinguistics 13 (5): 634-658.

Bolet, Diane. 2021. "Drinking Alone: Local Socio-Cultural Degradation and Radical Right Support - The Case of British Pub Closures." Comparative Political Studies p. (forthcoming).

Broz, J. Lawrence, Jeffry Frieden, and Stephen Weymouth. 2020. “Populism in Place: The Economic Geography of the Globalization Backlash." International Organization p. (forthcoming).

Cantoni, Davide, Felix Hagemeister, and Westcott Mark. 2017. "Persistence and Activation of Right-Wing Political Ideology." Munich Discussion Paper No. 2017-14. 
Charnysh, Volha, and Evgeny Finkel. 2017. "The death camp Eldorado: political and economic effects of mass violence." American political science review 111 (4): 801818.

Charnysh, Volha, and Leonid Peisakhin. 2022. "The Role of Communities in the Transmission of Political Values: Evidence from Forced Population Transfers." British Journal of Political Science 52 (1): 238-258.

Choi, Donghyun Danny, Mathias Poertner, and Nicholas Sambanis. 2019. "Parochialism, social norms, and discrimination against immigrants." Proceedings of the National Academy of Sciences 116 (33): 16274-6279.

Cinelli, Carlos, and Chad Hazlett. 2020. "Making Sense of Sensitivity: Extending Omitted Variable Bias." Journal of the Royal Statistical Society: Series B (Statistical Methodology) 82 (1): 39-67.

Cohen, William W, Pradeep Ravikumar, Stephen E Fienberg et al. 2003. A Comparison of String Distance Metrics for Name-Matching Tasks. In IIWeb. Vol. 2003 pp. 73-78.

Colantone, Italo, and Piero Stanig. 2018a. "Global Competition and Brexit." American Political Science Review 112 (2): 201-218.

Colantone, Italo, and Piero Stanig. 2018b. “The Trade Origins of Economic Nationalism: Import Competition and Voting Behavior in Western Europe." American Journal of Political Science 62 (4): 936-953.

Cramer, Katherine J. 2016. The Politics of Resentment. University of Chicago Press.

Cramer, Katherine Walsh. 2012. "Putting Inequality in Its Place: Rural Consciousness and the Power of Perspective." American Political Science Review 106 (3): 517-532.

Cremaschi, Simone, Paula Rettl, Massimo Marco, and Catherine E. De Vries. 2022. "Geographies of Discontent: How Public Service Deprivation Increased Far-right Support in Italy." OSF Working Paper, https://osf.io/5s2cu/. 


\section{References}

Du Bois, Inke. 2019. "Linguistic discrimination across neighbourhoods: Turkish, USAmerican and German names and accents in urban apartment search." Journal of Language and Discrimination 3 (2): 92-119.

Edwards, John. 2009. Language and identity: An introduction. Cambridge University Press.

Edwards, John. 2013. Sociolinguistics: A very short introduction. Vol. 365 Oxford University Press.

Eliasoph, Nina. 2017. "Recognition of Rural Pride and Poverty: Better Late than Never!" Political Communication 34 (1): 138-141.

Elspaß, Stephan. 2005. "Zum Wandel im Gebrauch regionalsprachlicher Lexik. Ergebnisse einer Neuerhebung." Zeitschrift für Dialektologie und Linguistik pp. 1-51.

Elspaß, Stephan, Adrian Leemann, Robert Möller, and Timo Grossenbacher. 2018. Grüezi, Moin, Servus! Wie wir wo sprechen. Rowohlt rororo.

Enos, Ryan D. 2014. "Causal Effect of Intergroup Contact on Exclusionary Attitudes." Proceedings of the National Academy of Sciences 111 (10): 3699-3704.

Falck, Oliver, Stephan Heblich, Alfred Lameli, and Jens Südekum. 2012. “Dialects, Cultural Identity, and Economic Exchange." Journal of Urban Economics 72 (2-3): 225239.

Fitzgerald, Jennifer. 2018. Close to Home: Local Ties and Voting Radical Right in Europe. Cambridge University Press.

Fitzgerald, Jennifer, and Duncan Lawrence. 2011. "Local cohesion and radical right support: The case of the Swiss People's Party." Electoral Studies 30 (4): 834-847.

Garrett, Peter. 2010. Attitudes to Language. Cambridge University Press.

Gellner, Ernest. 1993. Nations and nationalism. Cornell University Press. 


\section{References}

Gidron, Noam, and Peter A. Hall. 2017. "The Politics of Social Status: Economic and Cultural Roots of the Populist Right." British Journal of Sociology 68 (S1): S51-S80.

Goodhart, David. 2017. The Road to Somewhere: The Populist Revolt and the Future of Politics. Oxford University Press.

Grogger, Jeffrey, Andreas Steinmayr, and Joachim Winter. 2020. The wage penalty of regional accents. Technical report National Bureau of Economic Research.

Guiso, Luigi, Helios Herrera, Massimo Morelli, and Tommaso Sonno. 2020. “Economic Insecurity and the Demand of Populism in Europe." Working Paper, heliosherrera.com/populism.pdf.

Haffert, Lukas. 2021. “The Long-Term Effects of Oppression: Prussia, Political Catholicism, and the Alternative für Deutschland." American Political Science Review p. (forthcoming).

Hangartner, Dominik, Elias Dinas, Moritz Marbach, Konstantinos Matakos, and Dimitrios Xefteris. 2019. “Does Exposure to the Refugee Crisis Make Natives More Hostile?" American Political Science Review 113 (2): 442-455.

Harteveld, Eelco, Joep Schaper, Sarah L De Lange, and Wouter Van Der Brug. 2018. "Blaming Brussels? The impact of (news about) the refugee crisis on attitudes towards the EU and national politics." JCMS: Journal of Common Market Studies 56 (1): 157-177.

Hechter, Michael. 1972. Internal Colonialism: The Celtic Fringe in British National Development. Transaction publishers.

Homola, Jonathan, Miguel M. Pereira, and Margit Tavits. 2020. “Legacies of the Third Reich: Concentration Camps and Out-group Intolerance." American Political Science Review pp. 1-18.

Hooghe, Liesbet, and Gary Marks. 2016. Community, scale, and regional governance: a postfunctionalist theory of governance, Volume II. Oxford University Press. 
Imai, Kosuke, and Marc Ratkovic. 2014. "Covariate Balancing Propensity Score." Journal of the Royal Statistical Society: Series B (Statistical Methodology) 76 (1): 243-263.

Imbens, Guildo W. 2003. "Sensitivity to Exogeneity Assumptions in Program Evaluation." American Economic Review 93 (2): 126-132.

Inglehart, Ronald, and Pippa Norris. 2016. “Trump, Brexit, and the Rise of Populism: Economic Have-Nots and Cultural Backlash." SSRN, com/sol3/papers.cfm?abstract_id=2818659.

Iversen, Torben, and David Soskice. 2020. Democracy and Prosperity: Reinventing Capitalism Through a Turbulent Century. Princeton University Press.

Klingemann, Hans-Dieter. 2009. The Comparative Study of Electoral Systems. Oxford University Press.

Kurer, Thomas. 2020. "The declining middle: Occupational change, social status, and the populist right." Comparative Political Studies 53 (10-11): 1798-1835.

Kustov, Alexander. 2020. "Borders of Compassion: Immigration Preferences and Parochial Altruism." Comparative Political Studies p. (forthcoming).

Labov, William. 1963. "The Social Motivation of a Sound Change." Word 19 (3): 273-309.

Laitin, David D. 1992. Language repertoires and state construction in Africa. Cambridge University Press.

Lameli, Alfred, Volker Nitsch, Jens Südekun, and Nikolaus Wolf. 2014. "Same Same But Different: Dialects and Trade." German Economic Review 16 (3): 290-306.

Leemann, Adrian. 2021. "Apps for Capturing Language Variation and Change in German-Speaking Europe: Opportunities, Challenges, Findings, and Future Directions." Linguistics Vanguard 7 (s1).

Leemann, Adrian, Curdin Derungs, and Stephan Elspaß. 2019. "Analyzing Linguistic Variation and Change Using Gamification Web Apps: The Case of German-Speaking Europe." Plos One 14 (12): 1-29. 
Lipset, Seymour M., and Stein Rokkan. 1967. Party Systems and Voter Alignments. New York: Free Press.

Maxwell, Rahsaan. 2019. "Cosmopolitan Immigration Attitudes in Large European Cities: Contextual or Compositional Effects?" American Political Science Review 113 (2): $456-474$.

Maxwell, Rahsaan. 2020. “Geographic Divides and Cosmopolitanism: Evidence From Switzerland." Comparative Political Studies 53 (13): 2061-2090.

Mills, Anne E. 1985. "The Acquisition of German." The cross-linguistic study of language acquisition 1: 141-254.

Munis, B Kal. 2020. "Us over here versus them over thereâ! literally: Measuring place resentment in American politics." Political Behavior pp. 1-22.

Munis, B. Kal. 2021. "Place, candidate roots, and voter preferences in an age of partisan polarization: Observational and experimental evidence." Political Geography 85 (October 2019): 102345.

Mushaben, Joyce Marie. 2020. "A Spectre Haunting Europe: Angela Merkel and the Challenges of Far-Right Populism." German Politics and Society 38 (1): 7-29.

Patana, Pauliina. 2020. "Changes in local context and electoral support for the populist radical right: Evidence from Finland." Party Politics 26 (6): 718-729.

Pierson, Paul. 2011. "Politics in time." In Politics in Time. Princeton University Press.

Piketty, Thomas. 2020. Capital and Ideology. Harvard University Press Cambridge.

Polenz, Peter. 2009. Geschichte der deutschen Sprache. Walter de Gruyter.

Purnell, Thomas, William Idsardi, and John Baugh. 1999. "Perceptual and phonetic experiments on American English dialect identification." Journal of language and social psychology 18 (1): 10-30. 


\section{References}

Rakić, Tamara, Melanie C. Steffens, and Amélie Mummendey. 2011. "When it matters how you pronounce it: The influence of regional accents on job interview outcome." British Journal of Psychology 102 (4): 868-883.

Remlinger, Kathryn. 2009. “Everyone up Here: Enregisterment and Identity in Michigan's Keweenaw Peninsula." American Speech 84 (2): 118-137.

Remlinger, Kathryn A. 2017. Yooper Talk: Dialect as Identity in Michigan's Upper Peninsula. University of Wisconsin Press.

Rodden, Jonathan. 2019. Why Cities Lose: The Deep Roots of the Urban-Rural Political Divide. New York, NY: Basic Books.

Rokkan, Stein. 2009. Citizens, Elections, Parties: Approaches to the Comparative Study of the Processes of Development. ECPR Press.

Rokkan, Stein, and Derek W Urwin. 1983. Economy, Territory, Identity: Politics of West European Peripheries. Sage Publications.

Rydgren, Jens. 2008. “Immigration sceptics, xenophobes or racists? Radical rightwing voting in six West European countries." European Journal of Political Research 47 (6): 737-765.

Schaeffer, Merlin, Ruud Koopmans, Susanne Veit, Mareike Wagner, and Jonas Wiedner. 2011. "The Ethnic Diversity and Collective Action Survey (Edcas): Technical Report." WZB Discussion Paper, https://www.ssoar.info/ssoar/handle/document/23806.

Schmitt-Beck, Rüdiger, Hans Rattinger, Sigrid Roßteutscher, and Bernhard Weßels. 2010. "Die deutsche Wahlforschung und die German Longitudinal Election Study (GLES)." In Gesellschaftliche Entwicklungen im Spiegel der empirischen Sozialforschung. Springer pp. 141-172.

Scott, James C. 1998. Seeing like a state: How certain schemes to improve the human condition have failed. Yale University Press. 
Segrest Purkiss, Sharon L., Pamela L. Perrewé, Treena L. Gillespie, Bronston T. Mayes, and Gerald R. Ferris. 2006. "Implicit sources of bias in employment interview judgments and decisions." Organizational Behavior and Human Decision Processes 101 (2): 152-167.

Tajfel, Henri Ed. 1978. Differentiation Between Social Groups: Studies in the Social Psychology of Intergroup Relations. Academic Press.

Tajfel, Henri, M.G. Billig, and R.P. Bundy. 1971. “Social categorization and intergroup behaviour." European Journal of Soc 1(2): 149-178.

Upton, Clive, and John David Allison Widdowson. 2013. An Atlas of English Dialects: Region and Dialect. Routledge.

Voigtländer, Nico, and Hans-joachim Voth. 2012. "Persecution Perpetuated: The Medieval Origins of Anti-Semitic Violence in Nazi Germany." Quarterly Journal of Economics 127 (3): 1339-1392.

Wagner, Gert G, Joachim R Frick, and Jürgen Schupp. 2007. "The German SocioEconomic Panel Study (SOEP)-evolution, Scope and Enhancements.".

Weber, Eugen. 1976. Peasants Into Frenchmen The Modernization of Rural France, 18701914. Stanford University Press. 


\section{A Appendix}

\section{A Appendix}

\section{Contents}

A.1 Relation to $($ Haffert 2021$) \ldots \ldots \ldots \ldots \ldots \ldots$ A2

A.2 Summary statistics and coding decisions ..................... A3

A.2.1 County-level data ................... A3

A.2.2 Individual-level data $(\mathrm{GLES}) \ldots \ldots \ldots \ldots \ldots \ldots$ A . . . . . . . . . . .

A.3 Respondents per county $\ldots \ldots \ldots \ldots \ldots \ldots \ldots$ A8

A.4 Correlates of dialectal distance . . . . . . . . . . . . . A8

A.5 Dialectal distance measures - additional information . . . . . . . . . A12

A.6 Additional results . . . . . . . . . . . . . . . . . A13

A.6.1 Correlations between variables in the GLES data . . . . . . . . . . . A14

A.6.2 Results for the AfD in 2013, 2017 and $2021 \ldots$. . . . . . . . . . . A A15

A.6.3 Results for other parties . . . . . . . . . . . . . . . A15

A.7 Robustness and sensitivity . . . . . . . . . . . . . . . A16

A.7.1 Uncertainty in the dialectal distance measure . . . . . . . . . . . . A2O

A.7.2 Accounting for post-treatment bias . . . . . . . . . . A22

A.7.3 GLES: results showing covariates coefficients . . . . . . . . . . . . A23

A.7.4 GLES: voting for all radical right parties . . . . . . . . . . . . . . A24

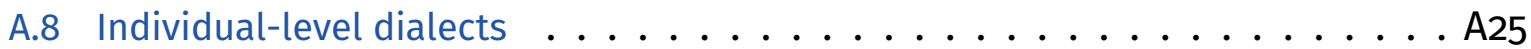

A.8.1 Data description \& estimation . . . . . . . . . . . . . A25

A.8.2 Prevalence of self-reported dialects . . . . . . . . . . . A28

A.8.3 Individual-level dialect and AfD support . . . . . . . . . . . . A31

A.9 Dialectal distance: self reported origins . . . . . . . . . . . . . . . A32

A.10 Dialectal distance: historical data . . . . . . . . . . . . . . . A33

A.11 Additional information on subjective social status data \& estimation . . . . . A34 


\section{A Appendix}

\section{A.1 Relation to (Haffert 2021)}

In Lipset and Rokkan's (1967) influential framework, several historical cleavages are hypothesized to affect contemporary politics (e.g. urban-rural; center-periphery; church-state). In the German context of $19^{\text {th }}$ century state formation, some of these cleavages overlapped (albeit never perfectly). For example, the Prussian state was dominated by Protestant forces and some of the cultural periphery was Catholic. Indeed, a Haffert (2021) has demonstrated the church-state conflict manifested itself in Prussian-led repression of certain Catholic regions, where AfD vote share is lower today.

But, it is crucial to note that much of the cultural-dialectic periphery of Germany was either Catholic and not subject to repression, or Protestant. This is consistent with the fact that our measure of the periphery (dialectic distance) does not correlate with Haffert's (2021) main independent variable, i.e. the interaction between state repression and Catholicism. The correlation between the two is $0.025 . .^{20}$ In short, the historical center-periphery divide matters, independent of the impact of historical church-state conflicts.

${ }^{20}$ We arrive at this number by calculating the correlation between Haffert's measure of church-state conflicts and our measure of dialectal distance. The former is defined as the product of his index of Kulturkampf intensity and his measure of the share of Catholics, which we obtained from his replication archive. We note that (i) we aggregate Haffert's data to the county level and (ii) we only assess West Germany, since Haffert does not have data on East Germany. 


\section{A Appendix}

\section{A.2 Summary statistics and coding decisions}

\section{A.2.1 County-level data}

Table A.1: Summary statistics, county-level

\begin{tabular}{lrrrrr}
\hline & Mean & SD & Min & Max & Valid obs. \\
\hline Dialectal distance & & & & & \\
Distance from standard German & 10.60 & 4.69 & 0.00 & 18.00 & 401 \\
Distance from standard German (Jaro-Winkler) & 0.17 & 0.09 & 0.00 & 0.33 & 401 \\
Aggregate voting outcomes & & & & & \\
AfD vote share 2017 (\%, party) & 13.39 & 5.33 & 4.94 & 35.46 & 400 \\
AfD vote share 2017 (\%, candidate) & 12.09 & 5.91 & 0.00 & 37.40 & 400 \\
County-level covariates & & & & & \\
CDU/CSU vote share 2017 (\%, party) & 43.29 & 7.41 & 25.98 & 63.47 & 400 \\
Tot. population (1000s) & 206.46 & 242.16 & 34.27 & 3613.49 & 401 \\
Pop. density / km2 & 533.60 & 702.71 & 36.00 & 4686.00 & 401 \\
Nominal GDP (EUR) & 7269.56 & 9094.59 & 1087.70 & 109571.23 & 399 \\
Nominal wage (EUR) & 3698.72 & 4567.90 & 530.08 & 52825.89 & 399 \\
Share Catholic (2011) & 0.33 & 0.24 & 0.02 & 0.88 & 392 \\
Unemployment rate (\%) & 6.46 & 3.15 & 1.40 & 16.70 & 392 \\
Out-migration / capita (internal, 2017) & 0.04 & 0.02 & 0.02 & 0.20 & 398 \\
In-migration / capita (internal, 2017) & 0.04 & 0.01 & 0.02 & 0.12 & 398 \\
Combined migration / capita (internal, 2017) & 0.08 & 0.03 & 0.04 & 0.31 & 398 \\
In-commuters / capita (2017) & 0.15 & 0.11 & 0.03 & 0.75 & 399 \\
Out-commuters / capita (2017) & 0.16 & 0.05 & 0.05 & 0.31 & 399 \\
Avg. in-commuting distance (km, 2017) & 48.51 & 17.14 & 14.73 & 122.15 & 398 \\
Avg. out-commuting distance (km, 2017) & 54.64 & 20.27 & 19.69 & 158.11 & 398 \\
Dist. to state capital (km) & 84.95 & 57.26 & 0.00 & 267.02 & 400 \\
Pogroms in 1920s (o/1) & 0.79 & 0.41 & 0.00 & 1.00 & 401 \\
NSDAP vote share, 1933 (\%) & 45.31 & 11.03 & 15.60 & 78.21 & 396 \\
\hline Notes: The Tably
\end{tabular}

Notes: The Tableshows summary statistics for all dependent and independent variables on the county level. The total number of counties is 401 . The last column gives the number of counties for which the variable in question is not missing. 


\section{A.2.2 Individual-level data (GLES)}

\section{Summary statistics:}

Table A.2: Summary statistics, individual-level (GLES)

\begin{tabular}{lccc}
\hline \hline \multicolumn{1}{c}{ Variable } & Mean & Std. Dev. & N \\
\hline Vote for AfD (party vote) & 0.085 & 0.279 & 33,675 \\
AfD likability scalometer (1-11) & 3.309 & 2.919 & 41,493 \\
Vote for radical right (party vote) & 0.094 & 0.292 & 33,675 \\
Female (binary) & 0.495 & 0.5 & 49,050 \\
Age (18-88) & 51.106 & 13.906 & 49,050 \\
Unemployed (binary) & 0.068 & 0.252 & 49,050 \\
Income (1-13) & 6.485 & 2.607 & 48,294 \\
Education (0-4) & 2.374 & 1.181 & 49,050 \\
Rurality (1-5) & 2.572 & 1.493 & 48,834 \\
East (binary) & 0.197 & 0.398 & 49,050 \\
Nationalism scale (1-5) & 3.459 & 1.005 & 4,444 \\
Local attachment (1-5) & 3.719 & 1.071 & 6,686 \\
National attachment (1-5) & 3.932 & 0.950 & 6,648 \\
\hline
\end{tabular}

Question wording and recoding: Below we report the original question wordings (translated into English) along with re-coding decisions. We also list the variable label in the original data set in square brackets, if applicable.

- Electoral district (2017)

- Description: information on respondents' electoral district based on location s/he resides.

- Question wording: none

- Re-coding: none

- Respondent ID

- Description: numeric identifier for each respondent, constant across waves

- Question wording: none

- Re-coding: none

- Wave

- Description: identifier for each of the 18 waves in GLES survey

- Question wording: none 


\section{A Appendix}

- Re-coding: none

- Vote for AfD (Zweitstimme) [kp*_19obb]

- Description: Respondents' vote intention for Zweitstimme (party vote)

- Question wording: 'Which of the following parties would you vote for with your Zweitstimme?'

- Re-coding: coded 1 if AfD, o otherwise, missings excluded.

- Vote for radical right (Zweitstimme) [kp*_19obb]

- Question wording: see above.

- Re-coding: Coded 1 if radical right party (AfD, NPD, Rep, die Rechte), o otherwise, missings excluded.

- AfD likability scalometer (1-11) [kp*_430i]

- Description: likeability scale for all parties in German Bundestag

- Question wording: 'Generally speaking what do you think about each of the following parties?' Response: I don't like the party at all (-5); I like the party a lot $(+5)$

- Re-coding: missings excluded.

- Female (binary) [kpx_2280]

- Question wording: none

- Re-coding: 1 if female, o otherwise.

- Age (18-88) [kpx_2290]

- Question wording: none

- Re-coding: year of survey - year of birth [kpx_2290]

- Unemployed (binary) [kp*_2340]

- Description: whether respondent was unemployed during survey fieldwork

- Question wording: 'Moving on with questions on your employment and profession: Out of the following list what applies to you?' Response: currently unemployed 


\section{A Appendix}

- Re-coding: Re-coded to 1 if respondent is currently unemployed, o otherwise.

- Income (1-13) [kp1_2591]

- Description: net household income scale for all respondents in first wave

- Question wording: 'How high is the monthly net income of your household in total? We are talking about the sum, which is available after taxes and social security has been deducted.' Response: under 500 Euro (1); 10,000 or more (13)

- Re-coding: missing values were excluded.

- Education (o-4) [kp1_2320]

- Description: highest educational level of respondent

- Question wording: 'What is your highest school-leaving qualification' Response: (1) left without qualification; (5) Abitur; (9) still in school

- Re-coding: re-coded (9) into (1) because too few observations and equivalent with not having a qualifiation at the time of survey.

- Rurality (1-5) [kp1_260o]

- Description: Rurality of respondents' place of residency.

- Question wording: 'If you would characterize your place of residence, do you live in ...' Response: (1) major city - (5) rural area close to small towns

- Re-coding: missing values were excluded.

- East (binary) [kp1_2601]

- Description: East/West indicator

- Question wording: Based on information about state of residency and electoral districts

- Re-coding: Split into states formerly belonging to West and East Germany. In case of Berlin split by relying on electoral district information.

- Nationalism scale (1-5) [ (kp*_5000a + kp*_500ob + kp*_5000c ) / 3 ]

- Description: National identity as social identity (3 Item scale) 


\section{A Appendix}

- Question wording: 'Please outline whether the following statements apply to you or not: (A) It is very important for me to be German (B) When I talk about Germans I use 'we' and not 'they' (C) The adjective "german" fits me very well' Response: (1) doesn't apply at all; (5) fully applies.

- Re-coding: additive index, missing values were excluded.

- Local attachment (1-5) [kp*_2200a]

- Question wording: 'People feel different strength in belonging to Germany, Europe, states and municipalities. How does this work for you? How strong do you feel belonging to (A) your municipality?' Response: (1) strongly belonging; (5) not belonging at all

- Re-coding: Reversed to ease interpretation, missing values were excluded.

- National attachment (1-5) [kp*_2200c]

- Question wording: 'People feel different strength in belonging to Germany, Europe, states and municipalities. How does this work for you? How strong do you feel belonging to Germany?' Response: (1) strongly belonging; (5) not belonging at all

- Re-coding: Reversed to ease interpretation, missing values were excluded.

Differences between national attachment and nationalistic attitudes: As shown above, we use two distinct scales to measure (i) national attachment and (ii) nationalism. Conceptually, the national attachment scale is based on one survey item, which measures how strongly individuals express belonging to Germany, as opposed to Europe or sub-national entities. The nationalism scale is a composite of three survey items, and primarily measures how strongly a respondent's social identity is connected to their national identity. This scale includes measures of the importance of being German, using 'we' instead of 'they' to refer to Germans, and stating that the adjective 'German' fits the respondent well. The main conceptual difference between the two scales is therefore that the attachment scale merely measures whether respondents feel attached to Germany, while the nationalism scale primarily measures Germanness as a social identity. As we show in Table A.5, these two scales are related - the correlation between the two is about 0.6 . 


\section{A.3 Respondents per county}

Figure A.1: Spiegel dialect survey responses per county

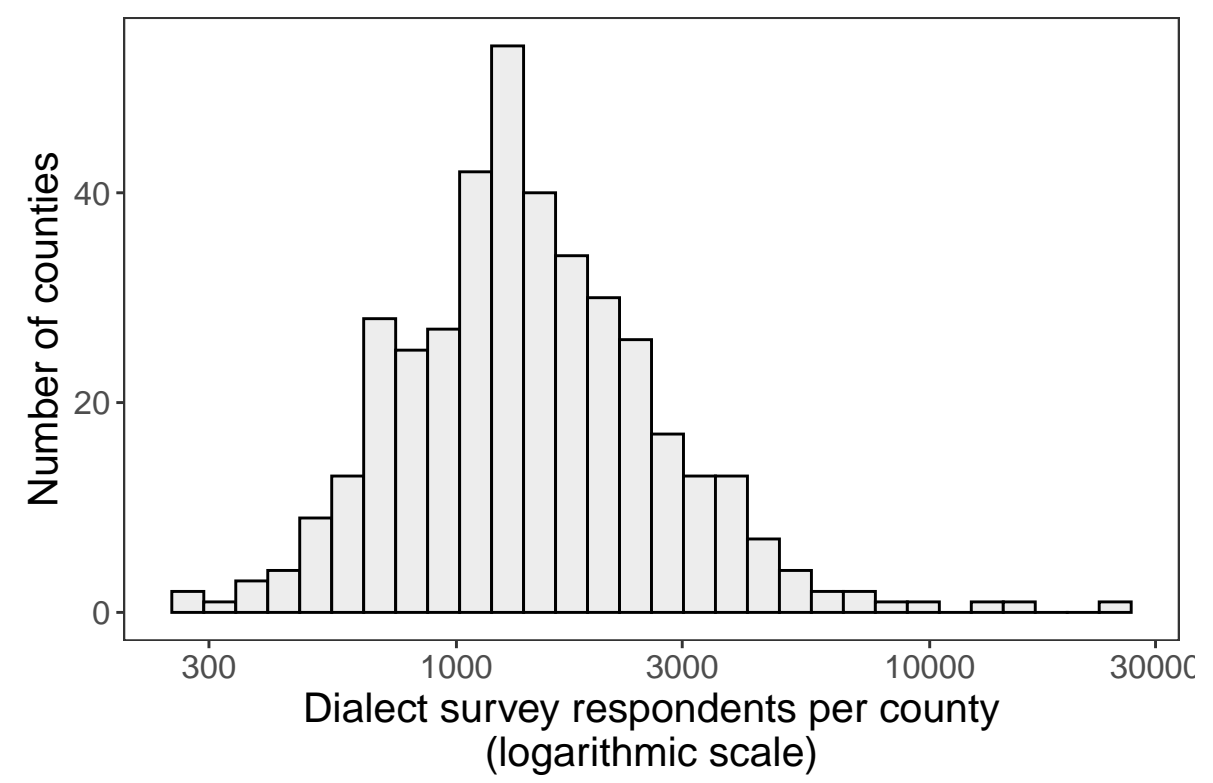

Note: The Figure shows the number of respondents per county. Since the distribution is skewed, we use a logarithmic scale for the $x$-axis.

\section{A.4 Correlates of dialectal distance}

To assess correlates of our dialectal distance measure, we rely on evidence from four different large-scale surveys in combination with aggregate data. We use the Ethnic Diversity and Collective Action Survey (EDCAS, see Schaeffer et al. 2011), the German Socio-Economic Panel (SOEP, see Wagner, Frick, and Schupp 2007), the German Longitudinal Election Study (GLES, see Schmitt-Beck et al. 2010) as well the German sample of the Comparative Study of Electoral Systems (CSES, see Klingemann 2009).

Our first data source is the 2010 Ethnic Diversity and Collective Action Survey (EDCAS, see Schaeffer et al. 2011). With an effective sample size of around 5,200, EDCAS is a large and comprehensive survey that includes, in addition to socio-economic and demographic information, a large number of survey items related to attitudes towards immigrants, social capital, social cohesion and trust. From EDCAS, we select survey items that ask respondents to report on civic engagement, local contact with natives and migrants as well as the amount of time a respondent has lived in the local area. For each respondent, we also observe the zip code area where he or she resides. Since German zip code areas are smaller than counties, we could theoretically disaggregate the Spiegel dialect survey responses to the zip-code level. 


\section{A Appendix}

However, we refrain from doing so since (1) we want to keep the unit of measurement constant and (2) smaller geographic disaggregation comes at the cost of imprecise measurement. In addition to the county-level dialectal distance measure, the EDCAS models include controls for gender, age, education, county-level population density, county-level unemployment rate as well as state fixed effects.

The second data source is the German Longitudinal Election Study (GLES, see SchmittBeck et al. 2010), which was conducted during the 2017 general election. GLES was created to capture political attitudes, behavior and knowledge among the German population. From GLES, we obtain a number of items that relate to attitudes towards immigration. These include preferences for future immigration policy, perceived salience of immigration as a policy issues as well as support for multiculturalism as opposed to assimilation of immigrants. Unlike the other three surveys, GLES does not include information on the county where respondents live. Rather, it reports the electoral district. Therefore, we aggregate the dialectal distance measure to the electoral district rather than the county level. Electoral districts are slightly bigger than counties, but remain roughly comparable in size. There are about 300 electoral districts and about 400 counties, and electoral districts frequently consist of just one county. The GLES consists of multiple waves. We generally only include the last wave for which a given correlate of dialectal distance was measured, i.e. all models are cross-sectional. In addition to the county-level dialectal distance measure, the EDCAS models include controls for gender, age, education, income, a rural/urban dummy as well as state fixed effects.

The third data source is the Comparative Study of Electoral Systems (CSES, see Klingemann 2009). A cross-national study, we use the German CSES sample. We select three characteristics, two of them related to attitudes towards elites, and a third one related to whether immigrants should adapt to the customs and traditions of the majority. As with the GLES data, the unit at which dialects are measured is the electoral district rather than the county. All CSES models include the following covariates: gender, education, employment status, household income, population density, unemployment rates as well as state fixed effects.

The last data source is the German Socio-Economic Panel (SOEP, see Wagner, Frick, and Schupp 2007). The SOEP is a large annual panel study with about 20,000 respondents per wave. We use two items from the 2018 SOEP. One of them asks respondents to rate how much they trust others in general (generalized trust). The other asks respondents whether they 


\section{A Appendix}

agree with the statement that refugees enrich the German culture. The covariates used in the SOEP are gender, education, household income, age, employment status as well as state fixed effects.

From each of the four surveys, we select a number of relevant correlates. We then regress each correlate on dialectal distance to standard German as well as a number of standard socio-economic controls and state fixed effects. To ease comparison between models, we standardize both the dialectal distance measure, as well as the correlates from the four survey data sets. We present the results in Table A.3, where each row displays the coefficient from regressing a given correlate on distance from standard German. 
Table A.3: Correlates of dialectal distance

\begin{tabular}{|c|c|c|c|c|c|}
\hline Characteristic & Estimate & SE & $\mathbf{N}$ & Year & Source \\
\hline \multicolumn{6}{|l|}{ 1. Scope of contact outside of region } \\
\hline In-migration ${ }^{a}$ & -0.121 & 0.089 & 392 & 2017 & Official data \\
\hline Out-migration $^{\mathrm{a}}$ & $-0.355^{* * *}$ & 0.123 & 392 & 2017 & Official data \\
\hline Avg. commuting distance (in) ${ }^{\mathrm{a}}$ & -0.093 & 0.107 & 392 & 2017 & Official data \\
\hline Avg. commuting distance (out) ${ }^{\mathrm{a}}$ & $-0.265^{* * *}$ & 0.098 & 392 & 2017 & Official data \\
\hline \multicolumn{6}{|l|}{$\begin{array}{l}\text { 2. Social ties \& contribution to commu- } \\
\text { nity }\end{array}$} \\
\hline Friends in neighborhood & 0.047 & 0.03 & 3665 & 2011 & EDCAS \\
\hline Years in the neighborhood & $0.062^{* *}$ & 0.025 & 3761 & 2011 & EDCAS \\
\hline Active in the cultural realm & $0.045^{* * *}$ & 0.017 & 3773 & 2010 & EDCAS \\
\hline Active in politics & $0.026^{*}$ & 0.015 & 3775 & 2010 & EDCAS \\
\hline Active in the social realm & 0.026 & 0.024 & 3772 & 2010 & EDCAS \\
\hline Voluntary service & $0.048^{* * *}$ & 0.018 & 2472 & 2010 & EDCAS \\
\hline Generalized trust & $-0.05^{* *}$ & 0.0237 & 17831 & 2018 & SOEP \\
\hline \multicolumn{6}{|l|}{ 3. Hostility towards outsiders } \\
\hline $\begin{array}{l}\text { Immigration of foreigners should be } \\
\text { limited }\end{array}$ & $0.256^{* *}$ & 0.13 & 1869 & 2017 & GLES \\
\hline Salience of immigration & -0.069 & 0.079 & 1879 & 2017 & GLES \\
\hline Support for multiculturalism & $-0.181^{*}$ & 0.108 & 1876 & 2017 & GLES \\
\hline Diversity is conflictual & $0.075^{* *}$ & 0.028 & 3659 & 2010 & EDCAS \\
\hline Local culture is harmed by immigrants & 0.076 & 0.075 & 1524 & 2017 & CSES \\
\hline Refugees enrich German culture & $-0.066^{* *}$ & 0.032 & 17680 & 2018 & SOEP \\
\hline $\begin{array}{l}\text { Minorities should adapt to the customs } \\
\text { and traditions of the majority } \\
\text { 4. Attitudes towards elites }\end{array}$ & 0.086 & 0.101 & 1527 & 2017 & CSES \\
\hline $\begin{array}{l}\text { People, not elites, should make policy } \\
\text { decisions }\end{array}$ & $0.119^{* *}$ & 0.059 & 1518 & 2017 & CSES \\
\hline Elites are trustworthy & -0.09 & 0.096 & 1518 & 2017 & CSES \\
\hline
\end{tabular}

Notes: The tables shows results from regressing selected survey items on dialectal distance from standard German. The results are from separate models, where the independent variable is always the standardized dialectal distance from standard German. All outcomes are standardized. Estimates are given in first column, standard errors are given in the second column. All models include socio-economic and demographic covariates as well as state fixed effects. For more information on the model specifications and data sources, see section A.4. ${ }^{a}$ These results are based on county-level offical statistics rather than survey data. Data was obtained from the German Federal Statistical Office.

${ }^{* * *} p<.01 ;{ }^{* *} p<.05 ;{ }^{*} p<.1$ 


\section{A Appendix}

\section{A.5 Dialectal distance measures - additional information}

Figure A.2: Correlates between historical and contemporary measures of dialectal distance

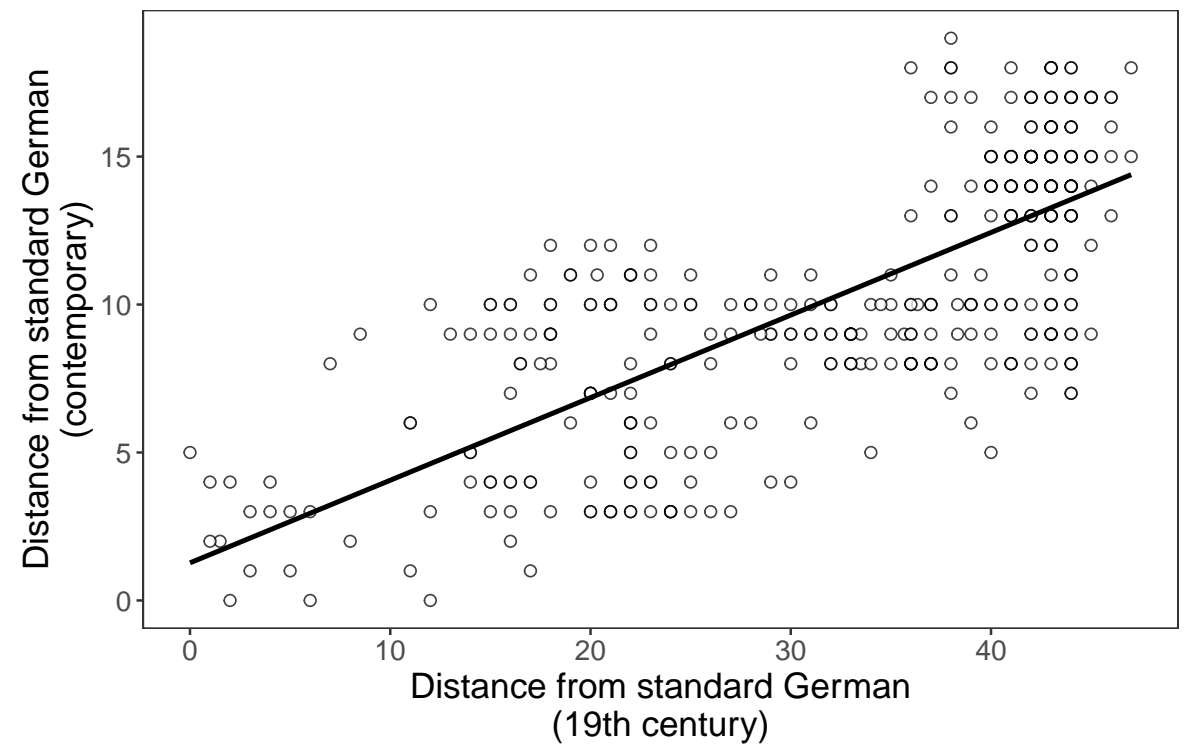

Note: The Figure shows the relationship between the $18^{\text {text }}$-century Wenker dialectal distance and the Spiegel measure. Greater values on both axes indicate greater dialectal distance from standard German. Note that both measures have different ranges. The solid line represents the predicted relationship from a linear model.

Figure A.3: Dialectal distance and AfD vote shares in 2017

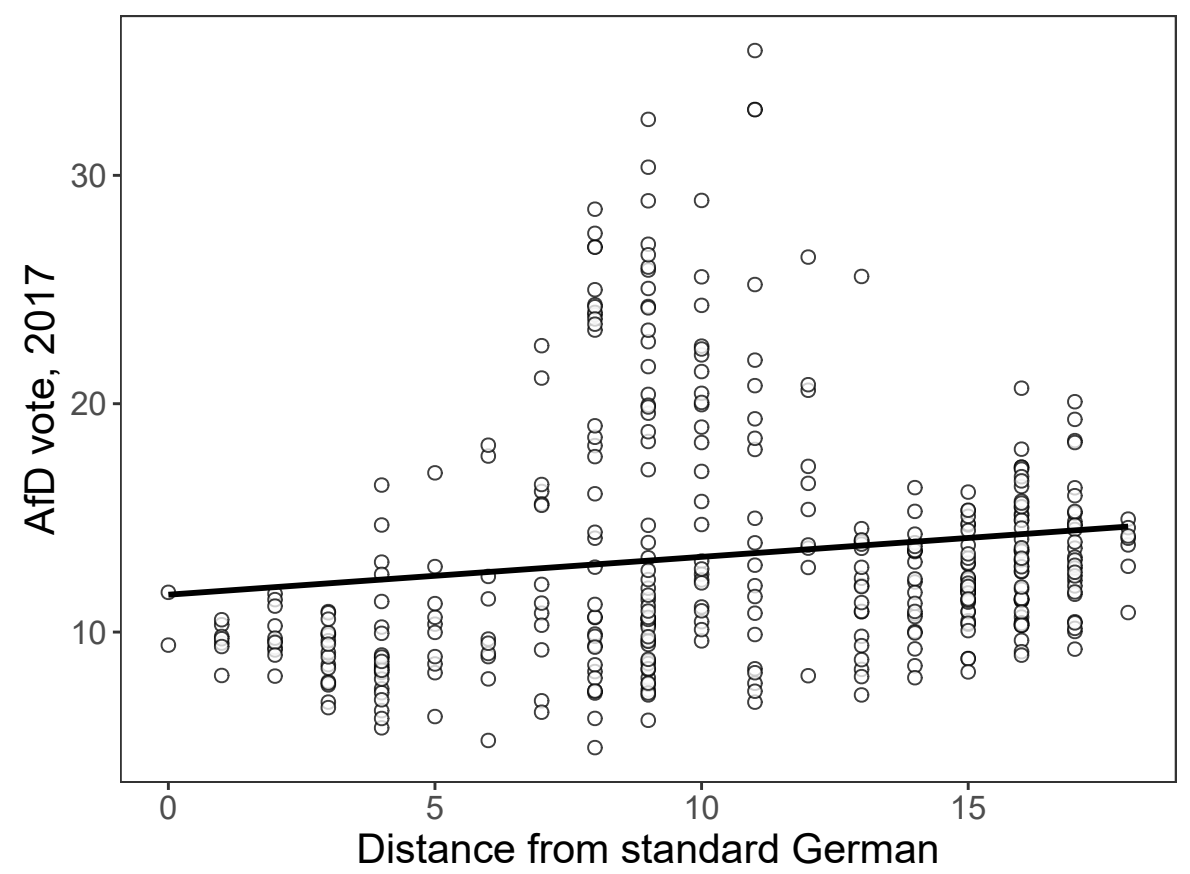

Note: Greater values on the x-axis indicate greater dialectal distance from standard German. The solid line represents the predicted relationship from a linear model. 


\section{A.6 Additional results}

Table A.4: Effects of dialectal distance on radical right voting in 2017.

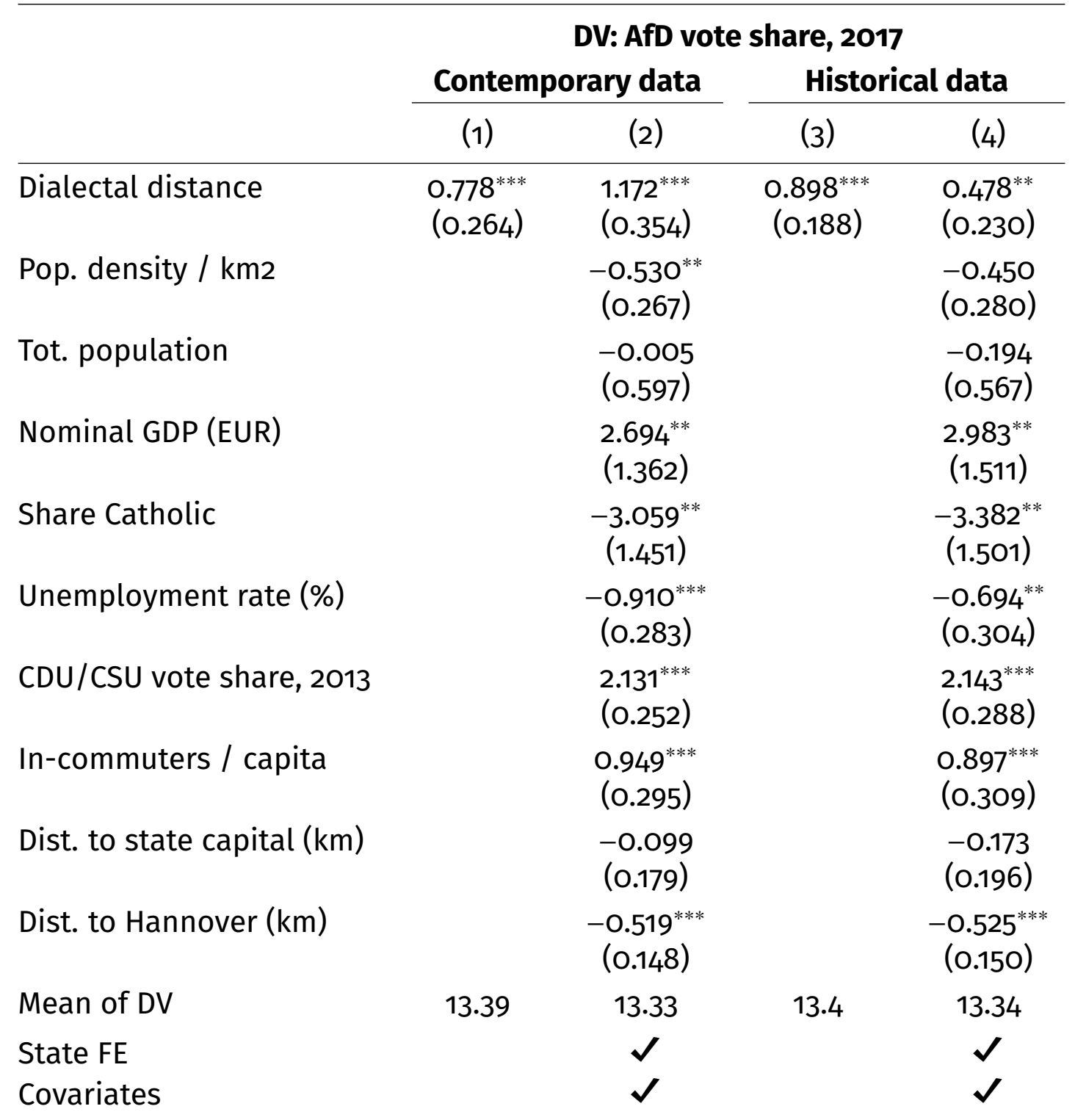

Notes: Standard errors are shown in parentheses. The dialectal distance measure and all covariates are standardized. The first two models use the contemporary dialectal distance measures, while the latter two models use the $19^{\text {th }}$-century measure. The county-level covariates are given in the table. This table contains the same models as Table 1. ${ }^{* * *} p<.01{ }^{* *} p<.05 ;{ }^{*} p<.1$ 


\section{A.6.1 Correlations between variables in the GLES data}

Table A.5: Cross-correlation table - GLES data

\begin{tabular}{|c|c|c|c|c|c|c|c|c|c|c|c|}
\hline & $\begin{array}{l}\text { Dialectal } \\
\text { distance }\end{array}$ & $\begin{array}{l}\text { Nationalism } \\
\text { scale }\end{array}$ & $\begin{array}{l}\text { Local } \\
\text { attach- } \\
\text { ment }\end{array}$ & $\begin{array}{l}\text { National } \\
\text { attach- } \\
\text { ment }\end{array}$ & $\begin{array}{l}\text { Fe- } \\
\text { male }\end{array}$ & Age & $\begin{array}{l}\text { Unem- } \\
\text { ployed }\end{array}$ & Income & $\begin{array}{l}\text { Edu- } \\
\text { cation }\end{array}$ & Rurality & $\begin{array}{l}\text { East Ger- } \\
\text { many }\end{array}$ \\
\hline Dialectal distance & 1.00 & & & & & & & & & & \\
\hline Nationalism scale & 0.01 & 1.00 & & & & & & & & & \\
\hline Local attachment & -0.01 & 0.33 & 1.00 & & & & & & & & \\
\hline $\begin{array}{l}\text { National attach- } \\
\text { ment }\end{array}$ & -0.04 & 0.58 & 0.46 & 1.00 & & & & & & & \\
\hline Female & 0.01 & -0.01 & -0.02 & -0.02 & 1.00 & & & & & & \\
\hline Age & -0.00 & 0.16 & 0.16 & 0.18 & -0.04 & 1.00 & & & & & \\
\hline Unemployed & -0.01 & -0.01 & -0.09 & -0.07 & -0.03 & -0.07 & 1.00 & & & & \\
\hline Income & 0.00 & 0.01 & 0.08 & 0.11 & -0.11 & 0.06 & -0.27 & 1.00 & & & \\
\hline Education & -0.02 & -0.19 & -0.01 & -0.01 & -0.03 & -0.14 & -0.11 & 0.29 & 1.00 & & \\
\hline Rurality & 0.07 & 0.08 & 0.01 & 0.01 & 0.04 & 0.04 & -0.00 & 0.10 & -0.08 & 1.00 & \\
\hline East Germany & 0.09 & 0.03 & 0.06 & -0.02 & -0.00 & 0.01 & 0.02 & -0.13 & 0.10 & -0.09 & 1.00 \\
\hline
\end{tabular}

Notes: The Table contains correlations between the variables used for the GLES models (see also Table 2, where we present estimates from the models using this data). All variables are measured on the individual level, except for dialectal distance, which is measured on the level of the electoral district. 


\section{A Appendix}

\section{A.6.2 Results for the AfD in 2013, 2017 and 2021}

Table A.6: Effects of dialectal distance on radical right voting in three elections

\begin{tabular}{lccc}
\hline & \multicolumn{3}{c}{ DV: AfD Vote share } \\
\cline { 2 - 4 } & $\mathbf{2 0 1 3}$ & $\mathbf{2 0 1 7}$ & $\mathbf{2 0 2 1}$ \\
\hline Dialectal distance & 0.037 & $1.172^{* * *}$ & $1.205^{* * *}$ \\
& $(0.103)$ & $(0.354)$ & $(0.348)$ \\
$\mathrm{N}$ & 392 & 392 & 391 \\
$\mathrm{R}^{2}$ & 0.655 & 0.828 & 0.871 \\
State FE & $\checkmark$ & $\checkmark$ & $\checkmark$ \\
Covariates & $\checkmark$ & $\checkmark$ & $\checkmark$
\end{tabular}

Notes: Standard errors are shown in parentheses. The dialectal distance is standardized. All models use the contemporary dialectal distance measure as the outcome. We present results for three elections. The electoral results for the 2021 election are based on preliminary data. The county-level covariates are GDP/capita, average wages, population density, unemployment rate, total population, \% catholic, commuters per capita and distance to the respective state capital. All covariates are standardized. ${ }^{* * *} \mathrm{p}<.01 ;{ }^{* *} \mathrm{p}<.05 ;{ }^{*} \mathrm{p}<.1$

\section{A.6.3 Results for other parties}

Table A.7: Effects of dialectal distance on support for all parties

\section{DV: Vote share, 2017}

\begin{tabular}{lcccccc} 
& CDU/CSU & SPD & Left & Greens & FDP & AfD \\
\hline Dialectal distance & -0.142 & 0.141 & -0.188 & $-1.087^{* * *}$ & -0.166 & $1.172^{* * *}$ \\
& $(0.210)$ & $(0.321)$ & $(0.166)$ & $(0.277)$ & $(0.194)$ & $(0.354)$ \\
Mean of DV & 34.31 & 20.19 & 8.67 & 8.12 & 10.17 & 13.33 \\
$\mathrm{~N}$ & 392 & 392 & 392 & 392 & 392 & 392 \\
$\mathrm{R}^{2}$ & 0.953 & 0.901 & 0.946 & 0.779 & 0.759 & 0.828 \\
State FE & $\checkmark$ & $\checkmark$ & $\checkmark$ & $\checkmark$ & $\checkmark$ & $\checkmark$ \\
Covariates & $\checkmark$ & $\checkmark$ & $\checkmark$ & $\checkmark$ & $\checkmark$ & $\checkmark$ \\
\hline
\end{tabular}

Notes: Standard errors are shown in parentheses. The dialectal distance is standardized. The county-level covariates are GDP/capita, average wages, population density, unemployment rate, total population, \% catholic, commuters per capita and distance to the respective state capital. ${ }^{* * *} \mathrm{p}<.01 ;{ }^{* *} \mathrm{p}<.05 ;{ }^{*} \mathrm{p}<.1$ 


\section{A.7 Robustness and sensitivity}

Table A.8: Effects of dialectal distance on radical right voting - robustness

\begin{tabular}{|c|c|c|c|c|c|}
\hline & \multicolumn{5}{|c|}{ DV: AfD vote share, 2017} \\
\hline & Baseline & $\begin{array}{l}\text { Control: } \\
\text { 1920s } \\
\text { pogroms }\end{array}$ & $\begin{array}{l}\text { Control: } \\
\text { NSDAP } \\
\text { vote } \\
\text { share }\end{array}$ & $\begin{array}{l}\text { West } \\
\text { Germany }\end{array}$ & $\begin{array}{l}\text { East Ger- } \\
\text { many }\end{array}$ \\
\hline Dialectal distance & $\begin{array}{l}1.172^{* * *} \\
(0.354)\end{array}$ & $\begin{array}{l}1.171^{* * *} \\
(0.354)\end{array}$ & $\begin{array}{l}1.168^{* * *} \\
(0.356)\end{array}$ & $\begin{array}{c}1.028^{* * *} \\
(0.331)\end{array}$ & $\begin{array}{c}2.382 \\
(1.590)\end{array}$ \\
\hline Mean of DV & 13.33 & 13.33 & 13.36 & 11.37 & 22.36 \\
\hline $\begin{array}{l}\mathrm{N} \\
\mathrm{R}^{2}\end{array}$ & $\begin{array}{c}392 \\
0.828\end{array}$ & $\begin{array}{c}392 \\
0.828\end{array}$ & $\begin{array}{c}388 \\
0.828\end{array}$ & $\begin{array}{c}322 \\
0.530\end{array}$ & $\begin{array}{c}70 \\
0.701\end{array}$ \\
\hline State FE & $\checkmark$ & $\checkmark$ & $\checkmark$ & $\sqrt{ }$ & $\checkmark$ \\
\hline Covariates & $\checkmark$ & $\checkmark$ & $\checkmark$ & $\checkmark$ & $\checkmark$ \\
\hline
\end{tabular}

Notes: Standard errors are shown in parentheses. The dialectal distance is standardized. The first model is the same baseline model as in Table 1. In the second model, we additionally control for whether a current county experienced pogroms in the 1920s. In the third model, we control for the per capita number of new NSDAP members between 1925 and 1933. In the fourth model, we control for the per-capita number of internal out-migrants. The last two models split the sample into East and West Germany. The county-level covariates are GDP/capita, average wages, population density, unemployment rate, total population, \% catholic, commuters per capita and distance to the respective state capital. ${ }^{* * *} \mathrm{p}<.01 ;{ }^{* *} \mathrm{p}<.05 ;{ }^{*} \mathrm{p}<.1$

Table A.9: Effects of dialectal distance on radical right voting - Jaro-Winkler distance

DV: AfD Vote share, 2017

\begin{tabular}{lcccccc}
\cline { 2 - 7 } & \multicolumn{2}{c}{ Baseline } & Jaro-Winkler & $\begin{array}{l}\text { J-W, } \\
\text { West } \\
\text { Germany }\end{array}$ & $\begin{array}{l}\text { J-W, East } \\
\text { Germany }\end{array}$ \\
\hline Dialectal distance & $0.778^{* * *}$ & $1.172^{* * *}$ & $0.713^{* * *}$ & $1.288^{* * *}$ & $1.165^{* * *}$ & 1.938 \\
Mean of DV & $(0.264)$ & $(0.354)$ & $(0.265)$ & $(0.349)$ & $(0.326)$ & $(1.432)$ \\
$\mathrm{N}$ & 13.39 & 13.33 & 13.39 & 13.33 & 11.37 & 22.36 \\
$\mathrm{R}^{2}$ & 400 & 392 & 400 & 392 & 322 & 70 \\
State FE & 0.021 & 0.828 & 0.018 & 0.830 & 0.535 & 0.716 \\
Covariates & & $\checkmark$ & & $\checkmark$ & $\checkmark$ & $\checkmark$ \\
\hline
\end{tabular}

Notes: Standard errors are shown in parentheses. The dialectal distance measure is standardized. The first and second models are the same as in Table 1. The third and fourth models use standardized Jaro-Winkler distance instead of the distance measure given in section 4.1. The last two models split the sample into East and West Germany, using the standardized Jaro-Winkler distance as the independent variable. The county-level covariates are GDP/capita, average wages, population density, unemployment rate, total population, \% catholic, commuters per capita and distance to the respective state capital. ${ }^{* * *} \mathrm{p}<.01 ;{ }^{* *} \mathrm{p}<.05 ;{ }^{*} \mathrm{p}<.1$ 


\section{A Appendix}

Table A.10: Effects of dialectal distance on radical right voting - administrative district FE.

DV: AfD Vote share, 2017

\begin{tabular}{lcccc}
\cline { 2 - 5 } & \multicolumn{2}{c}{ Baseline distance } & \multicolumn{2}{c}{ Jaro-Winkler distance } \\
\hline Dialectal distance & $0.778^{* * *}$ & $1.607^{* * *}$ & $0.713^{* * *}$ & $1.397^{* * *}$ \\
& $(0.264)$ & $(0.407)$ & $(0.265)$ & $(0.406)$ \\
Mean of DV & 13.39 & 13.33 & 13.39 & 13.33 \\
$\mathrm{~N}$ & 400 & 392 & 400 & 392 \\
$\mathrm{R}^{2}$ & 0.021 & 0.872 & 0.018 & 0.871 \\
Admin. district FE & & $\checkmark$ & & $\checkmark$ \\
Covariates & & $\checkmark$ & & $\checkmark$
\end{tabular}

Notes: Standard errors are shown in parentheses. The first two models use the baseline dialectal distance measure, while the third and fourth model use Jaro-Winkler distance. Both distance measures are standardized. Instead of state fixed effects, we use lower-level adminstrative district fixed effects. The county-level covariates are GDP/capita, average wages, population density, unemployment rate, total population, \% catholic, commuters per capita and distance to the respective state capital. ${ }^{* * *} \mathrm{p}<.01 ;{ }^{* *} \mathrm{p}<.05 ;{ }^{*} \mathrm{p}<.1$ 


\section{A Appendix}

Table A.11: Effects of dialectal distance on radical right voting - control coefficients \& controlling for distance to Hannover and distance to the border

DV: AfD Vote share, 2017

Dialectal distance

Pop. density / km2

Tot. population

Nominal GDP (EUR)

Share Catholic

Unemployment rate (\%)

CDU/CSU vote share, 2013

In-commuters / capita

Dist. to state capital $(\mathrm{km})$

Dist. to Hannover (km)

Dist. to Border (km)

$$
\begin{aligned}
& 0.778^{* * *} \\
& (0.264)
\end{aligned}
$$$$
1.705^{* * *}
$$$$
0.862^{* * *}
$$$$
\text { (0.273) }
$$$$
1.596^{* * *}
$$$$
\text { (0.552) }
$$$$
1.184^{* * *}
$$$$
\text { (0.521) }
$$$$
\text { (0.273) }
$$$$
\begin{gathered}
-0.676^{* * *} \\
(0.260)
\end{gathered}
$$$$
-0.291
$$$$
\text { (0.588) }
$$$$
-0.106
$$$$
\text { (0.367) }
$$$$
-0.964^{* * *}
$$$$
\text { (0.290) }
$$$$
\text { 2.070*** }
$$$$
\text { (0.253) }
$$$$
0.999^{* * *}
$$$$
\text { (0.299) }
$$$$
-0.080
$$$$
\text { (0.181) }
$$$$
-0.500^{* * *}
$$$$
\text { (0.189) }
$$$$
\begin{gathered}
-1.094^{* *} \\
(0.519)
\end{gathered}
$$$$
-0.915
$$$$
0.208
$$$$
\text { (0.598) }
$$$$
\text { (0.413) }
$$

0.427

0.190

0.071

$\begin{array}{lll}(0.272) & (0.313) & (0.220)\end{array}$

\section{State FE}

$\mathrm{N}$

No

No

400

399

No

No

Yes

399

399

392

0.021

0.031

0.026

0.032

\section{State FE}

Notes: Standard errors are shown in parentheses. The dialectal distance is standardized. All models use the contemporary dialectal distance measures as the outcome. The county-level covariates are GDP/capita, average wages, population density, unemployment rate, total population, \% catholic, commuters per capita and distance to the respective state capital. The models also include distance to Hannover and distance to the German border as additional covariates. All covariates are standardized. ${ }^{* * *} \mathrm{p}<.01 ;{ }^{* *} \mathrm{p}<$ $.05 ;{ }^{*} p<.1$ 
Table A.12: Effects of dialectal distance on radical right voting - CBPS weights.

\begin{tabular}{|c|c|c|c|c|}
\hline & \multicolumn{4}{|c|}{ DV: AfD Vote share, 2017} \\
\hline & \multicolumn{2}{|c|}{ Baseline (weighted) } & \multirow{2}{*}{$\begin{array}{l}\text { West } \\
\text { Germany } \\
1.752^{* * *} \\
(0.203)\end{array}$} & \multirow{2}{*}{$\begin{array}{l}\text { East Ger- } \\
\text { many } \\
0.675 \\
(0.426)\end{array}$} \\
\hline Dialectal distance & $\begin{array}{c}2.024^{* * *} \\
(0.251)\end{array}$ & $\begin{array}{c}1.592^{* * *} \\
(0.233)\end{array}$ & & \\
\hline Mean of DV & 13.92 & 13.92 & 11.32 & 22.28 \\
\hline $\mathrm{N}$ & 392 & 392 & 322 & 70 \\
\hline $\mathrm{R}^{2}$ & 0.860 & 0.896 & 0.585 & 0.755 \\
\hline State FE & & $\checkmark$ & $\checkmark$ & $\checkmark$ \\
\hline Covariates & & $\checkmark$ & $\checkmark$ & $\checkmark$ \\
\hline CBPS weights & $\checkmark$ & $\checkmark$ & $\checkmark$ & $\checkmark$ \\
\hline \multicolumn{5}{|c|}{$\begin{array}{l}\text { Notes: Standard errors are shown in parentheses. The dialectal distance measure is stan- } \\
\text { dardized. The first two models are similar to the baseline models in Table } 1 \text {. We weight each } \\
\text { observations using weights given by the CBPS method (see Imai and Ratkovic } 2014) \text {. The } \\
\text { last two models split the sample into East and West Germany. The county-level covariates } \\
\text { are GDP/capita, average wages, population density, unemployment rate, total population, } \\
\% \text { catholic, commuters per capita and distance to the respective state capital. }{ }^{* * *} \text { p }<.01 \text {; }{ }^{* *} \text { p } \\
<.05 ;{ }^{*} p<.1\end{array}$} \\
\hline
\end{tabular}

Table A.13: Sensitivity analysis - full results.

\begin{tabular}{|c|c|c|c|c|c|}
\hline Variable & $\begin{array}{l}\text { Partial } \\
R^{2} \quad \text { w.r.t. } \\
\text { treatment }\end{array}$ & $\begin{array}{l}\text { Partial } \\
R^{2} \quad \text { w.r.t. } \\
\text { outcome }\end{array}$ & $\begin{array}{l}\text { Adjusted } \\
\text { estimate }\end{array}$ & $\begin{array}{l}\text { Adjusted } \\
\text { SE }\end{array}$ & $\begin{array}{l}\text { Adjusted t- } \\
\text { stat }\end{array}$ \\
\hline Pop. density / km2 & 0.01 & 0.01 & 1.10 & 0.35 & 3.12 \\
\hline Tot. population & 0.00 & 0.00 & 1.17 & 0.35 & 3.31 \\
\hline Nominal GDP & 0.00 & 0.01 & 1.13 & 0.35 & 3.20 \\
\hline Nominal wage & 0.01 & 0.01 & 1.12 & 0.35 & 3.16 \\
\hline Share Catholic (2011) & 0.03 & 0.03 & 0.96 & 0.35 & 2.70 \\
\hline Unemployment rate & 0.01 & 0.20 & 0.95 & 0.32 & 2.98 \\
\hline CDU/CSU vote share 2017 (party) & 0.00 & 0.03 & 1.16 & 0.35 & 3.31 \\
\hline Commuters / capita (2017) & 0.01 & 0.00 & 1.15 & 0.36 & 3.24 \\
\hline Dist. to state capital $(\mathrm{km})$ & 0.00 & 0.03 & 1.12 & 0.35 & 3.22 \\
\hline
\end{tabular}

Notes: Full results from the sensitivity analysis outlined in section 7. Each row outlines the reduction in effect sizes for a hypothetical unobserved confounder with the same partial correlations w.r.t radical right voting and dialectal distance from standard German as the current covariates. 


\section{A Appendix}

\section{A.7.1 Uncertainty in the dialectal distance measure}

As described in section 4.1, we use the county-specific modal quiz answers to calculate dialectal distance between a given county and standard German. Since the respondents in each county only constitute a sample of the overall county population, there is some uncertainty associated with our estimates of dialectal distance. We use a bootstrap approach to address this uncertainty. To implement this, we proceed as follows:

1. We sample from all 725,000 quiz respondents with replacement to form bootstrap sample $j$.

2. We then calculate county specific modal answers $X_{i, j}^{k}$ within the sample, and use the modal answers to calculate our main independent variable $d_{i, j}$. We note that this measure varies between bootstrap samples $j$.

3. We then estimate the main specification shown in section 5 , which gives us the sample-specific coefficient estimate $\hat{\beta}_{j}$.

We repeat steps 1-3 500 times, giving us a distribution of estimates $\hat{\beta}_{j}$ for $j \in$ $\{1, \ldots, 500\}$. This distribution allows us to quantify how much our estimates vary when we change the sample that is used to calculate the dialectal distance. We show the resulting distributions in figure A.4. We find that neither the distribution of $\hat{\beta}_{j}$ with or without adding covariates includes zero, indicating that measurement uncertainty does not lead us to falsely rejecting the null hypothesis of no effect. 


\section{A Appendix}
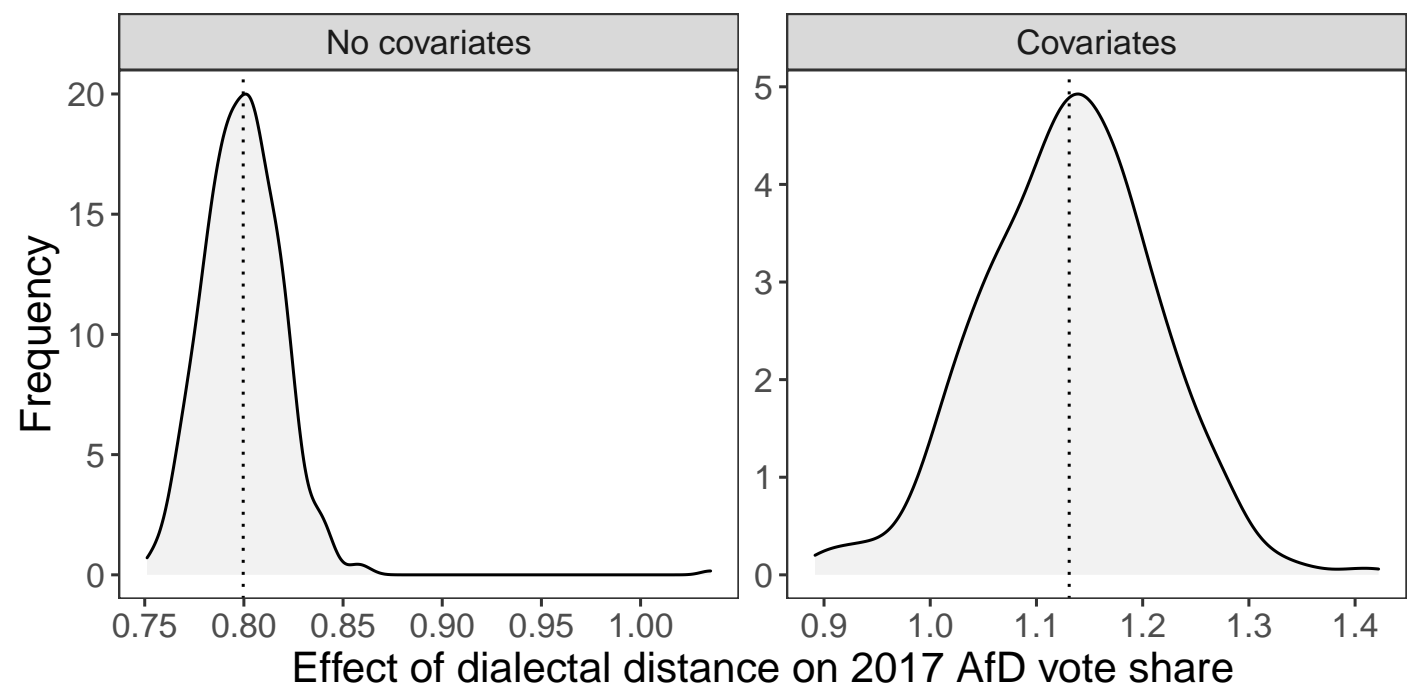

Figure A.4: Note: The figures show the distribution of the coefficient estimate $\hat{\beta}_{j}$ for 500 bootstrap samples. The left-hand panel shows the coefficient estimates from the model without covariates, while the right-hand side corresponds to the full model. The dotted vertical lines indicate the mean of each distribution. See the preceding discussion for more details. 


\section{A Appendix}

\section{A.7.2 Accounting for post-treatment bias}

In our main specification (see Table1), we run unconditional models, as well as models that condition on a range of contemporary variables. In a basic regression specification, this may induce post-treatment bias. Therefore, we rely on the sequential-g estimator, which allows us to include post-treatment controls without inducing posttreatment bias. For more information, we refer to Homola, Pereira, and Tavits (2020) for an example of the sequential-g estimator in a similar setting. In figure A.5, we compare the coefficient from the base specification that excludes covariates with the coefficient based on the sequential-g estimator. We find significant and positive effects in both cases. The sequential-g coefficient estimate is noticeable larger, although we caution against over-interpreting its magnitude.

Figure A.5: Comparing sequential-g estimates with unadjusted estimated

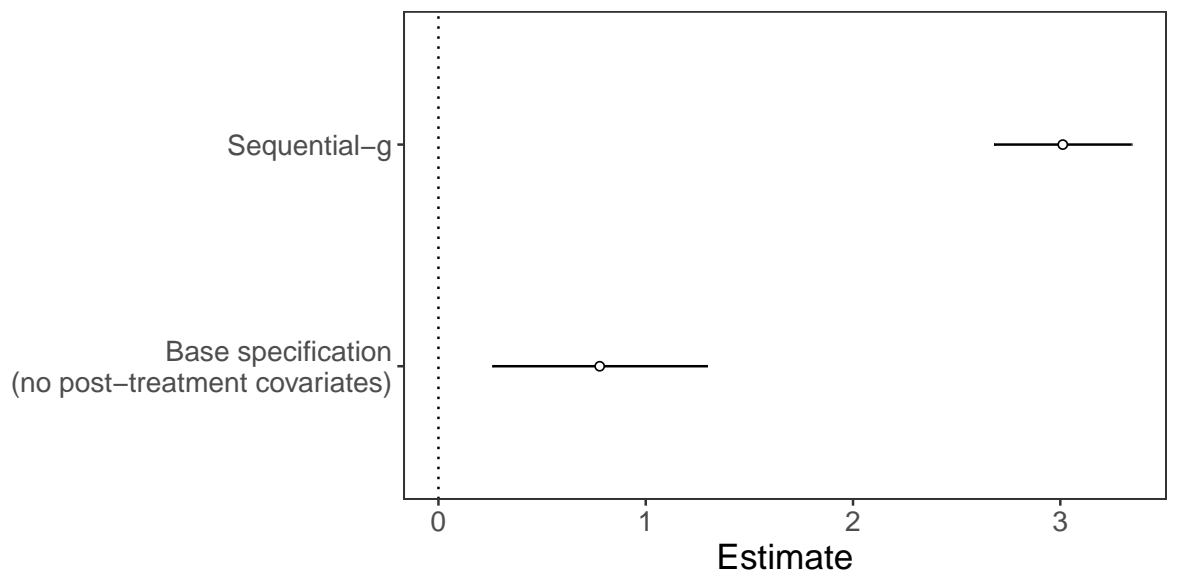

Note: The figure shows the unadjusted coefficient from the first model in Table1, as well as the sequential-g estimates, using bootstrapped standard errors. 


\section{A Appendix}

\section{A.7.3 GLES: results showing covariates coefficients}

Table A.14: Effects of dialectal distance on radical right voting intentions and likability.

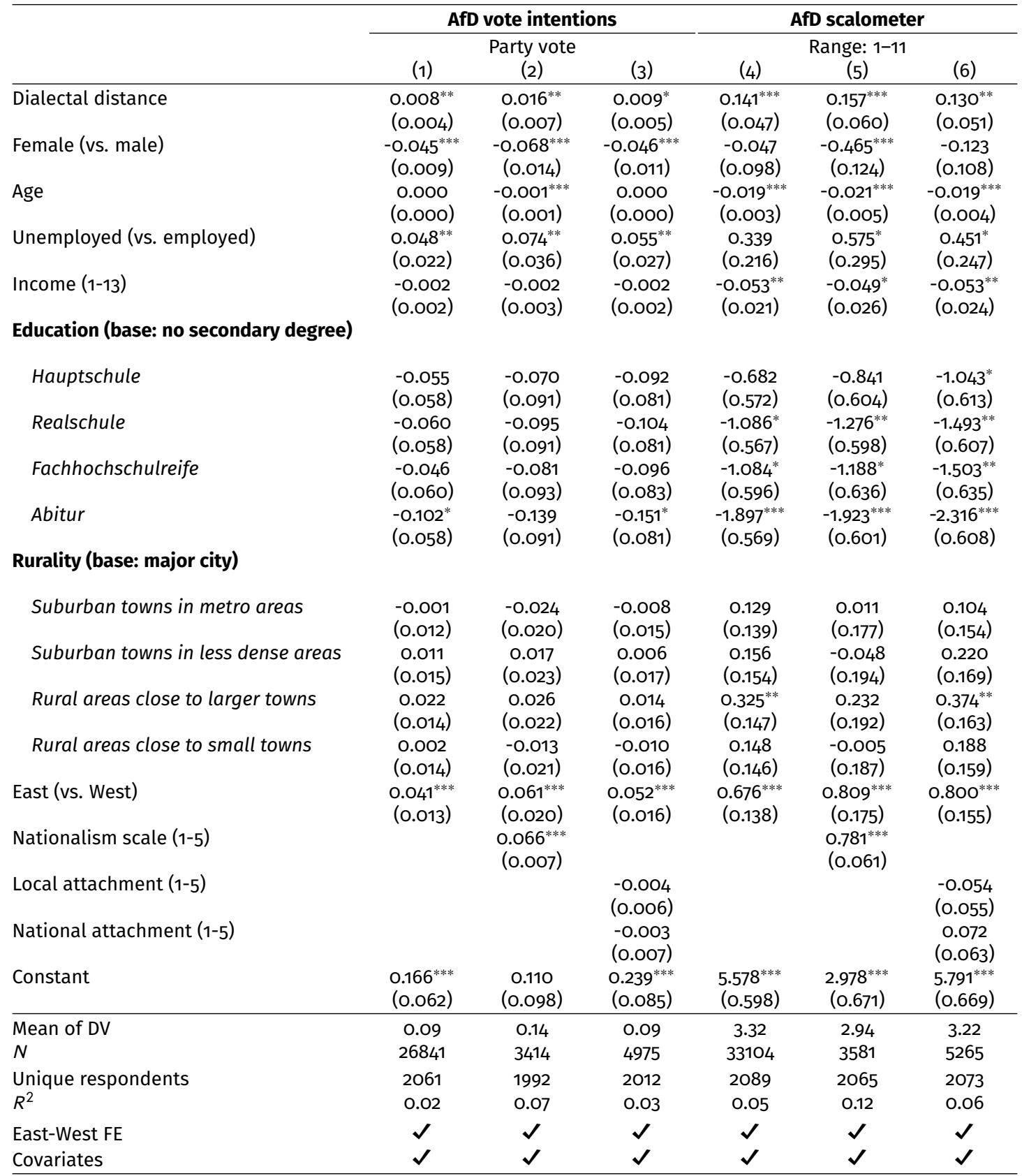

Notes: The Tablecontains coefficient estimates from six linear models. The main independent variable is dialectal distance to standard German, aggregated to the level of electoral districts. We pool 18 waves of the German Longitudinal Survey (GLES). Standard errors, clustered by respondent, are shown in parentheses. ${ }^{* * *} \mathrm{p}<.01$; $^{* *} \mathrm{p}$

$<.05{ }^{*} \mathrm{p}<.1$ 


\section{A Appendix}

\section{A.7.4 GLES: voting for all radical right parties}

In the Table below, we report additional results for the GLES / individual-level analyses. In the main body of the text, the outcome was whether respondents reported that they intend to vote for the AfD party. In Table A.15, we re-code the outcome such that all voters for any radical right party are coded as ' 1 ', which includes the AfD as well as the smaller NPD, Republikaner and Die Rechte parties.

Table A.15 shows the results using the alternative outcome that measure preferences for any radical-right party, not just the AfD. Using this alternative outcome, we find similar results as with the outcome that just measures AfD support.

Table A.15: Effects of dialectal distance on radical-right voting intentions, using all radical-right parties

\begin{tabular}{lccc}
\hline & \multicolumn{3}{c}{ DV: Radical right vote in- } \\
& $\begin{array}{c}\text { tentions } \\
(1)\end{array}$ & $(2)$ & $(3)$ \\
\hline Dialectal distance & $0.011^{* *}$ & $0.017^{* *}$ & $0.010^{* *}$ \\
& $(0.005)$ & $(0.007)$ & $(0.005)$ \\
Nationalism scale (1-5) & & $0.068^{* * *}$ & \\
& & $(0.007)$ & \\
Local attachment (1-5) & & & -0.005 \\
& & & $(0.006)$ \\
National attachment (1-5) & & & -0.002 \\
& & & $(0.007)$ \\
\hline Mean of DV & 0.10 & 0.14 & 0.10 \\
$N$ & 26841 & 3414 & 4975 \\
Unique respondents & 2061 & 1992 & 2012 \\
$R^{2}$ & 0.02 & 0.08 & 0.03 \\
East-West FE & $\checkmark$ & $\checkmark$ & $\checkmark$ \\
Covariates & $\checkmark$ & $\checkmark$ & $\checkmark$ \\
\hline
\end{tabular}

Notes: The table contains coefficient estimates from three linear models. The main independent variable is dialectal distance to standard German, aggregated to the level of electoral districts. We pool 18 waves of the German Longitudinal Survey (GLES). Standard errors, clustered by respondent, are shown in parentheses. ${ }^{* * *} p<.01 ;{ }^{* *} p<.05 ;{ }^{*} p<.1$ 


\section{A Appendix}

\section{A.8 Individual-level dialects}

\section{A.8.1 Data description \& estimation}

To provide additional information on individual rather than aggregate-level dialect measures, we rely on data from the German Socio-Economic Panel Survey (SOEP, see also section A.4). Specifically, we use data from the Innovation Sample in 2016 and 2017, a special sample that includes survey items that are not part of the standard SOEP questionnaire. The IS sample includes several survey items on whether respondents use dialects, as well as on individual background characteristics and the location where respondents reside. Based on this sample, we present additional results on (i) the correlation between aggregate and individual measures of dialect usage and (ii) the correlation between individual-level dialects and party preferences.

Measures of dialect: We rely on two explanatory variables that measure whether individuals use dialects. The first is a general item, which asks "Can you speak a German dialect or Low German?", and the second asks "Do you use dialect or Standard High German with colleagues?". In our analysis, both variables are binary - the first variable is equal to one if the respondents report being able to speak a dialect, and the second one is equal to one if respondents indicate using dialects at work. We chose two outcomes, since we aimed to measure gradations of dialect competency. The general dialect items measure only whether people can speak dialects (and not whether they use them regularly), while the second item measures whether respondents use dialects in a relatively formal environment. The "dialect at work" items therefore measures a much stronger form of dialect usage. We note that the second measure - using dialects at work - is only asked if respondents indicate that they can speak any dialect, which leads to a lower number of observations. In table A.16 below, we present information on the coverage of the data, particularly with respect to how many counties are covered. There are responses for 120 counties, which means that $30 \%$ of all German counties are covered by the data. The average number of respondents per county is 21.9, while the median number of respondents is 19. Covered 


\section{A Appendix}

counties tend to be, on average, larger than counties that are not covered. As a result, the total population of covered counties is about 37 million people, or about $44.7 \%$ of the total German population in 2017.

In figure A.6, we present additional information on differences between counties that are covered and counties that are not covered. Inclusion in the sample appears mostly uncorrelated with unemployment rates, commuting, and the share of Catholics. We do, however, observe that covered counties tend to be larger, more densely populated and have higher wages and higher GDP/capita. Finally, covered counties are slightly less supportive of the CDU/CSU party, and tend to be somewhat more distant from their respective state capitals. In sum, we caution that the SOEP-IS data only cover a minority of all counties in Germany. In addition, the counties that are covered tend to be higher-income, larger, and more densely populated counties.

Table A.16: SOEP-IS coverage

\begin{tabular}{l|c}
\hline Number of counties with any survey responses & 120 \\
$\%$ of counties covered & 30 \\
Mean number of responses per county & 21.9 \\
Median number of responses per county & 19 \\
$\%$ of total German population covered & 44.7 \\
\hline
\end{tabular}

Estimation: We estimate series of linear models, where the binary outcome measures whether respondents identify with the AfD party (the survey item is "Which party do you lean toward"). In addition, we control for the county county-level characteristics that we include in all of our main models, as well as the following individual-level variables: individual income, employment status, age, years of education, and gender. Finally, some models include state fixed effects. Since the dialect questions were asked in two waves (2016 and 2017), some respondents enter the sample twice. We use this pooled sample, but also add survey wave fixed effects and cluster by respondent to account for duplicate inclusions of some respondents. Finally, we also present models where we additionally control for the aggregate-level dialectal distance. The results of these models are given in Table A.18.

Instrumental variables: As an additional empirical strategy, we rely on an instru- 


\section{A Appendix}

Figure A.6: Correlates of SOEP-IS coverage

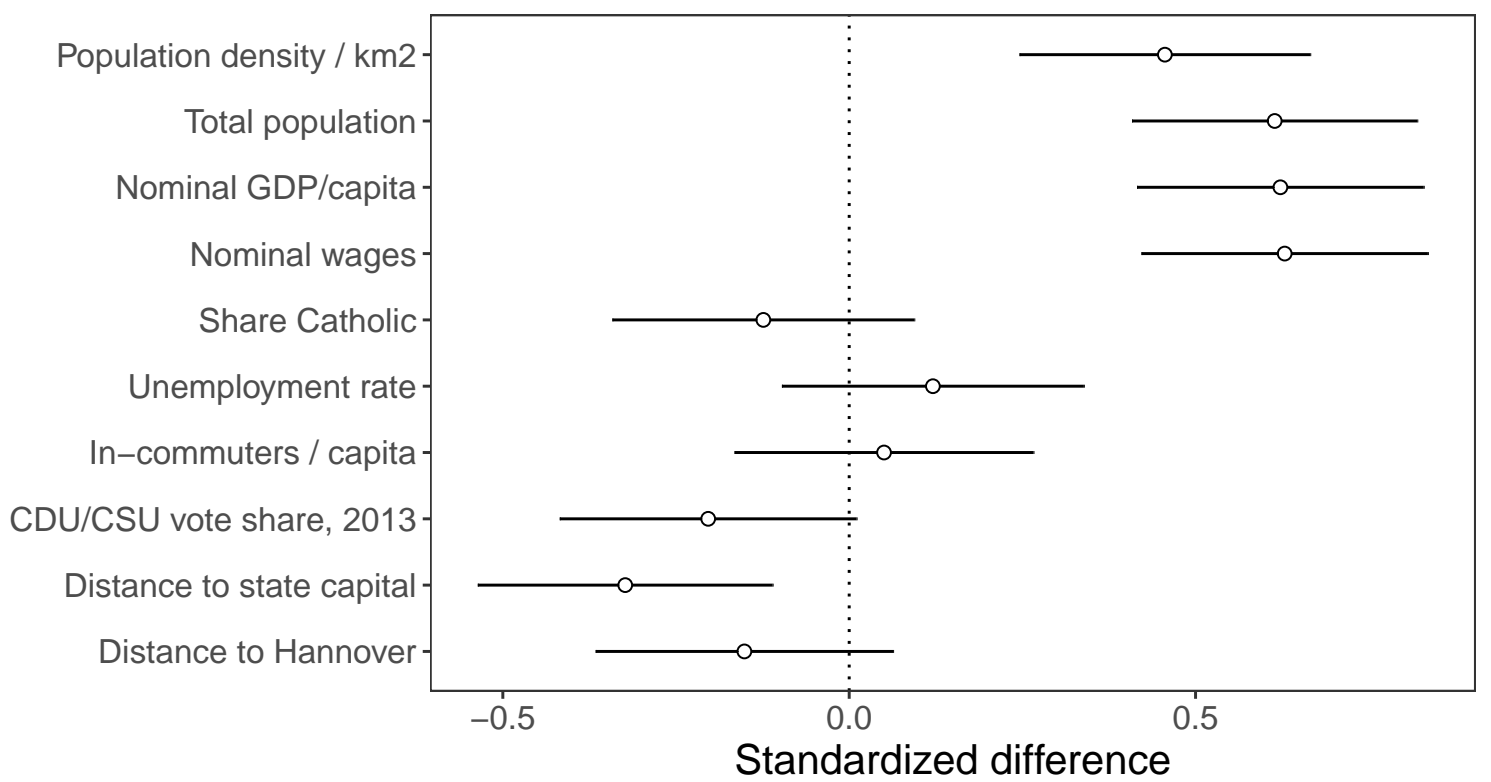

Notes: The figure presents information on differences between counties that are covered by the SOEP-IS data set, and counties that are not covered. Counties are defined as covered if there is at least one respondent from the county in the survey data. A total of 120 counties are covered, which leaves 281 counties that are not covered. The figure presents standardized differences, i.e. the difference is measured in standard deviations. Positive values indicate that the average for a given variable is higher in counties that are covered than in counties that are not covered.

mental variables design, where we instrument individual dialects with a proxy for the "linguistic enviroment" when survey respondents where in school. This is instrument was first used by Grogger, Steinmayr, and Winter (2020), who we follow in constructing the instrument. The instrument draws on the following survey item:

Think back to when you were in elementary school. How would you rate the speech of the majority of your classmates?

1. No regional accent (like a news anchor in the Tagesschau)

2. Weak regional accent

3. Medium regional accent

4. Rather strong regional accent

5. Very strong regional accent

The instrument used by Grogger, Steinmayr, and Winter (2020) is based on the observations that individuals partially acquire their dialect from peers. It measures 


\section{A Appendix}

the average response to the above question among survey respondents that live close to a given respondent. More formally, the instrument for respondent $i$ is defined as

$$
Z_{i}=\frac{1}{N_{\text {Neighbors }}} \sum_{j} X_{j}
$$

Where $j$ is a respondent from the set $\{j \mid j \neq i, j$ and $i$ are close $\}$. While Grogger, Steinmayr, and Winter (2020) use physical distance to define whether individuals $i$ and $j$ are "close", we rely on a somewhat simpler definition - we consider an individual $j$ to be close to $i$ if they reside in the same administrative district (see also section 7 for the definition of administrative districts). As we show in TableA.19, this definition leads to a relatively strong first stage, i.e. the instrument is strongly correlated with speaking any dialect. We note that this instrument may not fulfill the assumptions necessary for unbiased instrumental variable estimates. The exclusion restriction requires us to assume that regional linguistic environment during childhood only affects AfD party preferences through its effect on individual dialects. However, childhood linguistic environment likely correlates with, for example, regional development, connection to the rest of the country or urbanity. Therefore, we recommend exercising caution when interpreting the IV estimates in Table A.19.

\section{A.8.2 Prevalence of self-reported dialects}

We first demonstrate descriptively that (i) knowledge of dialects is common among SOEP respondents, and (ii) individual knowledge and usage of dialects is much more prevalent in regions that are more distant from standard German, as measured by our main dialectal distance measure. In figure A.7, we first show that about $50 \%$ of respondents report being able to speak any dialect. Of these $50 \%$, about $21 \%$ report speaking dialects at work. In counties with above-average dialectal distance, about $75 \%$ of respondents report being able to use dialects. In these regions, respondents are also about three times as likely to use dialects at work, compared to counties that are closer to standard German. Similarly, respondents in counties that 


\section{A Appendix}

Figure A.7: Dialect prevalence on the individual level

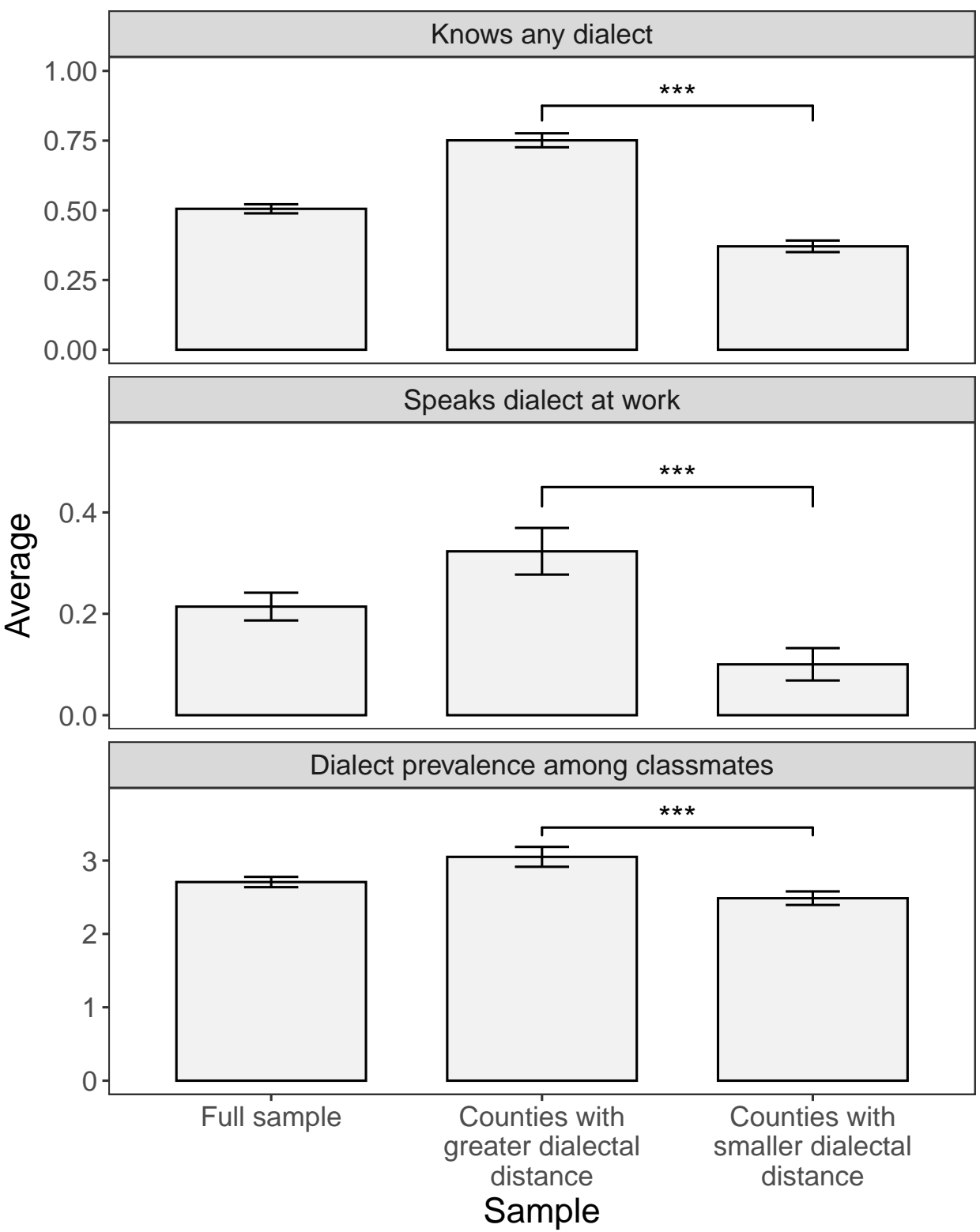

Note: The figure shows average values for the three individual-level dialect variables, for three different samples. The first two variables are binary, while the third is a five-point scale. We show averages for the whole sample, as well as for the set of counties with above-average aggregate dialectal distance, and the set of counties with below-average dialectal distance. For the latter two, we indicate whether the difference in means is statistically significant.

are more distant from standard German also report that speaking dialects was more common among their classmates in school. We further present correlations between the three dialect variables in table A.17. We note that the operationalization of the aggregate-level dialectal distance variable differs between figures A.7, which uses a binary split, and table A.17, which uses the original, continuous measure of dialect usage. Depending on the operationalization, the variable most strongly associated 


\section{A Appendix}

with aggregate-level dialects is either the "dialects at work" or the "knows any dialect variable". Since the exact strength of the association depends on the operationalization of the variable, there is no clear pattern regarding which of the two variable is clearly most strongly associated with aggregate-level dialect usage.

Taken together, this shows that our aggregate-level measure of dialects captures not only the presence but also the usage of dialects in everyday life.

Table A.17: Correlation between the aggregate-level and three individual-level dialect measures

\begin{tabular}{lc}
\hline & $\begin{array}{l}\text { Correlation with } \\
\text { aggreggate-level } \\
\text { dialectal distance }\end{array}$ \\
\hline Knows any dialect & 0.367 \\
Speaks dialect at work & 0.329 \\
Dialect prevalence among classmates & 0.255 \\
\hline
\end{tabular}

Notes: The table shows the correlation between each of the three individual-level dialect variables discussed above and the aggregate-level dialectal distance measure. 


\section{A.8.3 Individual-level dialect and AfD support}

Table A.18: Association between individual-dialect and AfD party preference (SOEP data)

\begin{tabular}{lcccccc}
\hline & \multicolumn{5}{c}{ DV: AfD party preference (o/1) } \\
\cline { 2 - 7 } Any dialect (indiv.) & $\begin{array}{c}0.005 \\
(0.010)\end{array}$ & $\begin{array}{c}0.001 \\
(0.013)\end{array}$ & $\begin{array}{c}-0.0003 \\
(0.013)\end{array}$ \\
Dialect at work (indiv.) & & & & $0.048^{* *}$ & $0.062^{*}$ & $0.062^{*}$ \\
& & & & $(0.022)$ & $(0.032)$ & $(0.032)$ \\
Covariates & & $\checkmark$ & $\checkmark$ & & $\checkmark$ & $\checkmark$ \\
State FE & & $\checkmark$ & $\checkmark$ & & $\checkmark$ & $\checkmark$ \\
Agg. dialectal distance & & & $\checkmark$ & & & $\checkmark$ \\
$\mathrm{R}^{2}$ & 0.000 & 0.067 & 0.068 & 0.011 & 0.156 & 0.159 \\
$\mathrm{~N}$ & 1,731 & 1,375 & 1,375 & 451 & 362 & 362 \\
\hline
\end{tabular}

Notes: Standard errors are shown in parentheses. We use two binary measures for whether respondents use dialects. The first measures whether respondents indicate speaking any dialect, and the second indicates whether they use dialects at work (conditional on saying yes to the first item). All models a binary indicator of AfD party preference as the outcome. The county-level covariates are GDP/capita, average wages, population density, unemployment rate, total population, \% catholic, commuters per capita and distance to the respective state capital. The individual-level covariates are individual income, employment status, age, years of education, and gender. We also present additional models where we add county-level dialectal distance as an additional covariates. ${ }^{* * *} \mathrm{p}$ $<.01 ;{ }^{* *} p<.05 ;{ }^{*} p<.1$

Table A.19: Association between individual-dialect and AfD party preference (SOEP data) - IV estimates

\begin{tabular}{lcccc}
\hline & \multicolumn{3}{c}{ DV: AfD party preference (o/1) } \\
\cline { 2 - 5 } Any dialect (indiv.) & 0.034 & 0.091 & & \\
Dialect at work (indiv.) & $(0.041)$ & $(0.103)$ & $0.155^{* *}$ & 0.323 \\
& & & $(0.072)$ & $(0.224)$ \\
Covariates & & $\checkmark$ & & $\checkmark$ \\
State FE & & $\checkmark$ & & $\checkmark$ \\
First stage F-stat & 121.795 & 21.808 & 58.907 & 7.977 \\
N & 1,731 & 1,375 & 451 & 362 \\
\hline
\end{tabular}

Notes: Standard errors are shown in parentheses. We use two binary measures for whether respondents use dialects. The first measures whether respondents indicate speaking any dialect, and the second indicates whether they use dialects at work (conditional on saying yes to the first item). All models a binary indicator of AfD party preference as the outcome. The county-level covariates are GDP/capita, average wages, population density, unemployment rate, total population, \% catholic, commuters per capita and distance to the respective state capital. The individual-level covariates are individual income, employment status, age, years of education, and gender. We also present additional models where we add county-level dialectal distance as an additional covariates. ${ }^{* * *} \mathrm{p}<.01 ;{ }^{* *} \mathrm{p}<.05 ;{ }^{*} \mathrm{p}$ $<.1$ 


\section{A Appendix}

\section{A.9 Dialectal distance: self reported origins}

As stated in Section 4.1, we use the dialect quiz data to construct aggregate-level measures of dialectal distance. This is based on self-reported information on the place where respondents grew up, rather than the place where they currently reside, if the two are not the same. We now elaborate why it appears reasonable to assume that respondents usually indicate the place where they grew up, rather than their current place of residence. We note that the original version of the dialect quiz is not online anymore, which is why we rely on Leemann, Derungs, and Elspaß (2019) and Leemann (2021) - these authors are the original creators of the dialect quiz.

The two studies document how the instructions in the dialect quiz strongly prime readers to indicate the place where they grew up. One example is the beginning of the quiz, where respondents are instructed as follows: "Sagen Sie uns wie Sie sprechen, und wir sagen Ihnen, woher Sie stammen" (Tell us how you speak, and we will tell your where you originate). The German verb "stammen" suggests that the quiz is about the location where respondents grew up, rather than the place where they currently reside (in the latter case, the instructions would use "leben" (live) or "wohnen" (reside) instead of "stammen" (originate from)). After completing the quiz, respondents are then presented with an estimate of the location where grew up. They are then given the following prompt: "Wo spricht man wirklich so wie Sie? Klicken Sie dafür in die Karte" (Where does one actually speak like you? To indicate this, please click on the map). This is the prompt that asks respondents to indicate their place of origin, which we then use to measure dialectal distance from standard German. The language used here again suggests that respondents to indicate their place of origin, as it asks them for the location where people speak like them. Assuming that a respondent has moved to a different area, we would expect that the location "where people speak like them" is the one where they grow up, and not the one where they currently reside. This is also reflected in the discussion in Leemann, Derungs, and Elspaß (2019) and Leemann (2021), who consistently use "regional origin" rather than "current place of residence" to refer to the location variable in their data. 


\section{A Appendix}

\section{A.10 Dialectal distance: historical data}

Our historical data is taken from the Deutsche Sprachatlas (see Falck et al. 2012; Lameli et al. 2014), a large-scale survey of the German language that was originally conducted in the late $19^{\text {th }}$ century. Based on the survey, we use a measure of dialectal distance between the dialect spoken in a given region, and the standard German dialect that is spoken in the Hannover area in Northern Central Germany. This dialectal distance measure measure serves as a proxy for cultural remoteness, our main independent variable.

Initiated by the Georg Wenker in 1879, the Deutscher Sprachatlas survey was aimed at documenting differences between regional dialects. Wenker surveyed over 40,000 elementary schools across the whole German Empire, asking students and teachers to translate 40 German sentences into the local dialects. Respondents were specifically asked to use phonetic spelling when translating the example sentences, preserving regional differences in pronunciation. In the first panel of Figure A.8, we show an example of the survey questionnaire as well as a map the regional variation in the word Kleid (cloth or dress). Based on the survey results, Wenker's successor Ferdinand Wrede then identified 66 'prototypical characteristics' of the German language, relating to spelling, pronunciation, grammar and differential use of cases. For each of the 66 characteristics, Wrede created maps that document their geographic variation within the German Empire.

We do not have direct access to the original surveys or the prototypical characteristics. Rather, we rely on an aggregated data set compiled by Lameli et al. (2014). They aggregate the Wenker surveys to the level of contemporary German counties. For possible pair between two counties, Lameli et al. (2014) create a measure of dialectal distance. We use part of this data to ascertain how close a county is to the standard German dialect that is spoken in Hannover. 


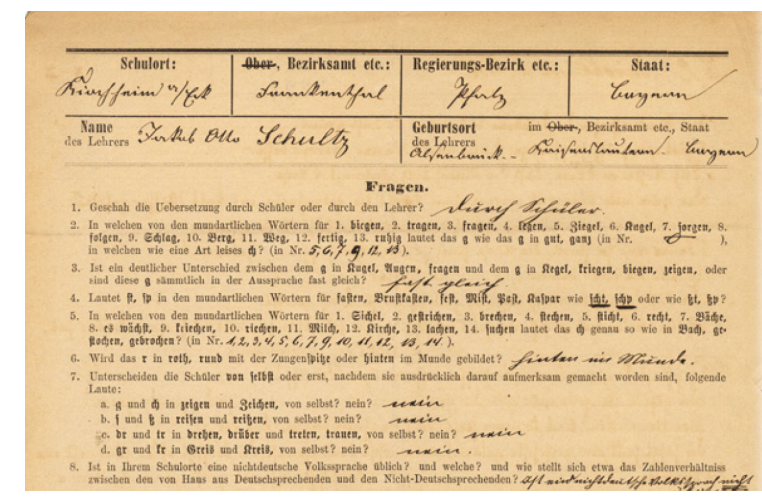

(a) Original dialect questionnaire of the language survey

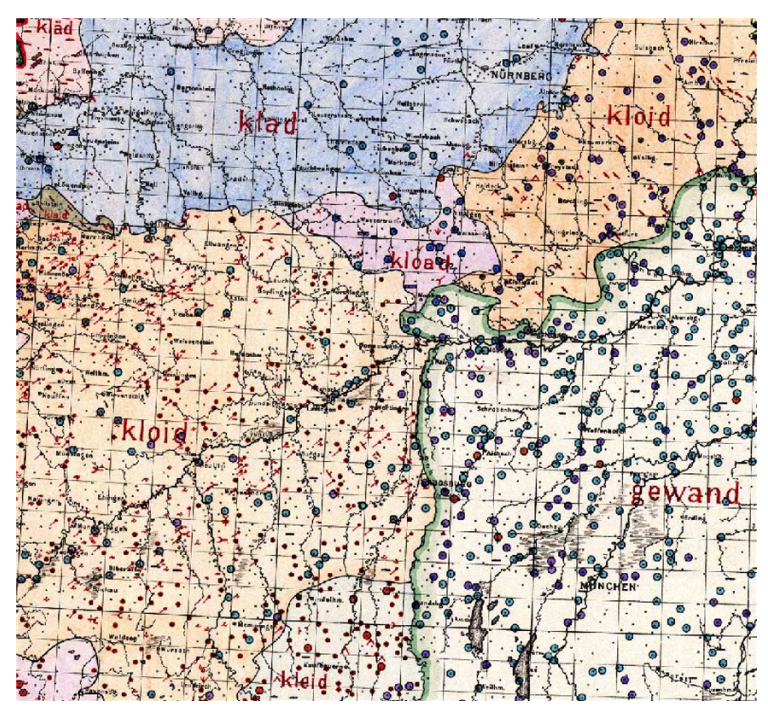

(b) Variation of the word 'Kleid', drawn by Georg Wenker

Figure A.8: Questionnaire and map by Georg Wenker

\section{A.11 Additional information on subjective social status data \& estimation}

In figure 3, we present the association between dialectal distance and self-perceived social status, based on individual-level data from the German Socio-Economic Panel (SOEP, see Wagner, Frick, and Schupp 2007) survey. Here we provide some further details on the data as well as on the estimation. While the SOEP is an annual panel, our outcome was measured only once in 2018, since it was part of an additional module of the survey. We reproduce the official translation of the prompt for the status item below:

“Please imagine this ladder shows where people are situated in their social environment. At the top, we can find people which have the highest social importance to their social environment. At the bottom, we can find people with the lowest importance to their social environment. Where would you place yourself on the ladder? The higher your position on that ladder is the more you are alike to people at the top. The lower your position is the more your are alike to people at the bottom. Please select the rung of the ladder where you find yourself currently in comparison to other people in your social environment."

Respondents are then shown an image of a ladder with ten rungs, and are asked to 


\section{A Appendix}

indicate the rung that most closely matches their perceived social status. This results in a variable that ranges from 1-10, where 10 is the highest rung on the ladder. For the sample that we base the results in figure 3 on, the mean self placement is about 6.3 with a standard deviation of about 1.6. Before estimating the association between dialects and self-perceived status, we standardize this variable such that it has a mean of zero and a standard deviation of one.

We then estimate a series of OLS models, where we use the county-level dialectal distance to Hannover as the main independent variable. Similar to the main specifications that use county-level data, we always include state fixed effects to account for unobserved regional heterogeneity. Depending on the specification, we add individual-level controls and county-level controls. The county-level controls are the same ones used in the main models (see Table 1). Individual-level controls are income, age, gender, years of education, employment status and political interest. Crucially, the individual-level controls can be seen as a proxy for the true social status, since we can condition on income, employment and education. Therefore, these covariates ensure that self-perceived social status is not simply a measure of income or education. We show results based on different model specifications in figure 3. For all models, we cluster standard errors by county. 